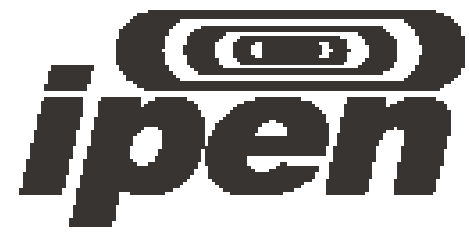

AUTARQUIA ASSOCIADA À UNIVERSIDADE DE SÃO PAULO

Medida Absoluta da atividade e determinação da probabilidade de emissão gama por decaimento do Lu-177

Fabrício Fernandes Vaz da Silva

Dissertação apresentada como parte dos requisitos para obtenção do Grau de Mestre em Ciências na Área de Tecnologia Nuclear - Aplicações

Orientador:

Prof. Dr. Mauro da Silva Dias 


\section{MEDIDA ABSOLUTA DA ATIVIDADE E DETERMINAÇÃO DA PROBABILIDADE DE EMISSÃO GAMA POR DECAIMENTO DO ${ }^{177} \mathrm{Lu}$}

FABRÍCIO FERNANDES VAZ DA SILVA

Dissertação Apresentada como parte dos requisitos para obtenção do Grau de Mestre em Ciências na Área de Tecnologia Nuclear - Aplicações

Orientador:

Dr. Mauro da Silva Dias

São Paulo

2011 
À minha mãe, Valéria

(em memória)

À minha esposa Cláudia 


\section{Agradecimentos:}

A Deus, por dirigir minha vida.

Ao Dr. Mauro da Silva Dias, orientador deste trabalho, pela enorme paciência, pela atenção, pelas valiosas instruções e pelas importantes lições.

À Dra. Marina Fallone Koskinas, pelo suporte técnico e pela assistência no trabalho do laboratório.

Aos colegas do Laboratório de Metrologia Nuclear, pela amizade.

Ao Instituto de Pesquisas Energéticas e Nucleares, pela oportunidade de realização do presente trabalho.

À minha esposa Claudia Veiga Ferreira Vaz, minha companheira e amiga, por todo o apoio.

A todos que de alguma forma colaboraram para a realização deste trabalho. 


\title{
MEDIDA ABSOLUTA DA ATIVIDADE E DETERMINAÇÃO DA PROBABILIDADE DE EMISSÃO GAMA POR DECAIMENTO DO ${ }^{177} \mathrm{Lu}$
}

\author{
Fabrício Fernandes Vaz da Silva
}

\section{RESUMO}

O presente trabalho teve como objetivo a padronização em atividade do radionuclídeo ${ }^{177} \mathrm{Lu}$, um importante radiofármaco utilizado no tratamento de câncer neuroendócrino. Este radionuclídeo se desintegra por emissão beta acompanhada de várias emissões gama simultâneas, o que tornou possível a aplicação do método de coincidência $4 \pi \beta-\gamma$. Para a detecção da radiação beta, foi utilizado um detector proporcional (PC), com geometria $4 \pi$, e dois cintiladores de $\mathrm{Nal}(\mathrm{TI})$ para a detecção da radiação gama. Os sinais gerados nos detectores passaram por amplificadores, discriminadores e módulos atrasadores, para serem enviados a um analisador multicanal. Para este experimento, foi utilizado um sistema de coincidências que aplica um módulo TAC (Time to Amplitude Converter), o qual converte diferença de tempo em amplitude de pulso. Para obter-se a variação na eficiência beta, foram acrescentados absorvedores de Collodion nas partes superior e inferior da fonte radioativa. Desta forma, foi possível extrapolar o valor para eficiência beta igual a $100 \%$, obtendo assim a atividade da fonte radioativa. A curva de extrapolação experimental foi comparada com a previsão teórica, obtida por meio do método de Monte Carlo. Além da padronização em atividade do ${ }^{177} \mathrm{Lu}$, também foram determinadas as suas probabilidades de emissão gama por decaimento para cada uma das principais transições gama, por meio de um espectrômetro de HPGe, previamente calibrado. 


\title{
ABSOLUTE ACTIVITY MEASUREMENT AND DETERMINATION OF GAMMA-RAY EMISSION PROBABILITY PER DECAY OF ${ }^{177}$ Lu
}

\author{
Fabrício Fernandes Vaz da Silva
}

\begin{abstract}
The present work aimed the activity standardization of radionuclide ${ }^{177} \mathrm{Lu}$, an important radioisotope used for treatment of neuroendocrine cancer. This radionuclide disintegrates by beta decay followed by several simultaneous gammaray emissions, which made possible the application of the $4 \pi \beta-\gamma$ coincidence method. For the detection of beta radiation in $4 \pi$ geometry a proportional detector (PC) was used, and for gamma radiation detection a pair of $\mathrm{Nal}(\mathrm{TI})$ scintillators was used. The signals generated by the detectors passed through amplifiers, discriminators and delay modules, and were sent to a multichannel analyzer. For the present experiment, the system includes a TAC (Time to Amplitude Converter) module which converts the time difference in pulse amplitude. To obtain the variation in beta efficiency, Collodion absorbers at the top and bottom of the radioactive source were applied. In this way, it was possible to extrapolate the beta efficiency value to $100 \%$, thereby obtaining the radioactive source activity. The extrapolated experimental curve was compared with the theoretical prediction, obtained by means of the Monte Carlo method. Besides the activity standardization of ${ }^{177} \mathrm{Lu}$, its gamma-ray emission probabilities per decay for the main gamma transitions were also determined by means of an HPGe spectrometer, previously calibrated.
\end{abstract}




\section{SUMÁRIO}

\section{Páginas}

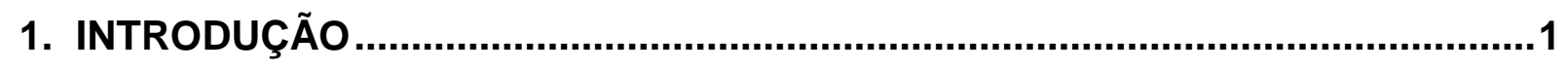

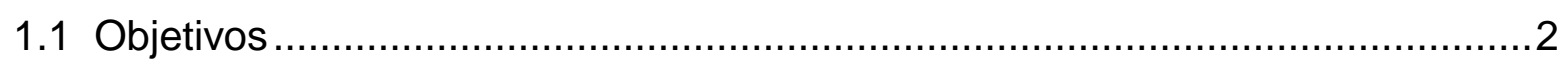

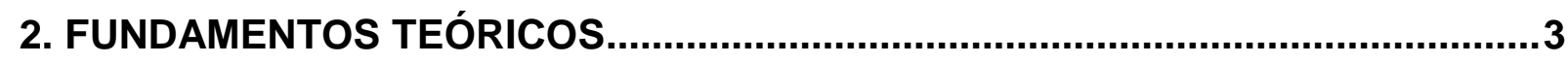

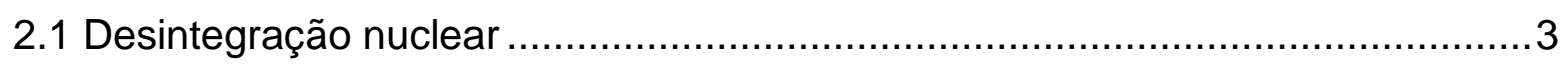

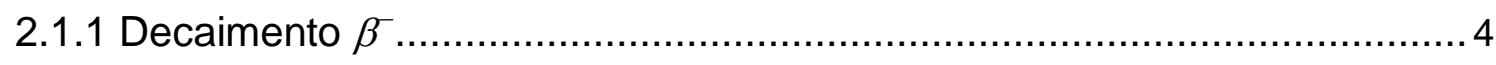

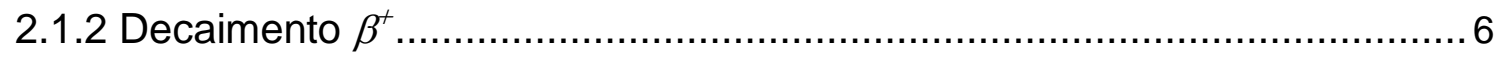

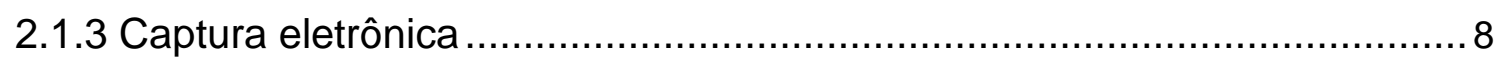

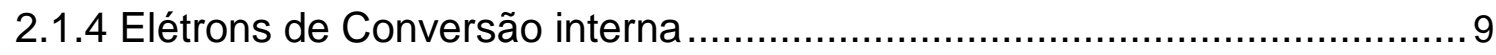

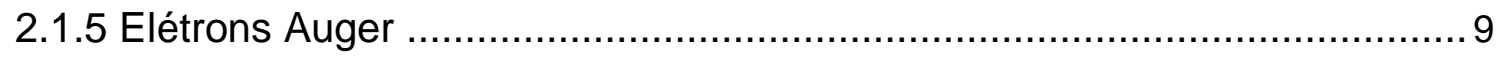

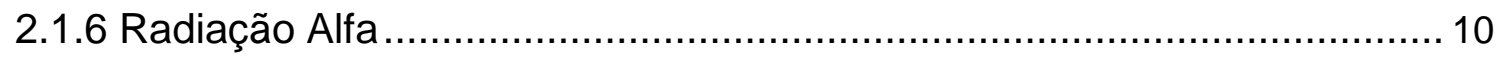

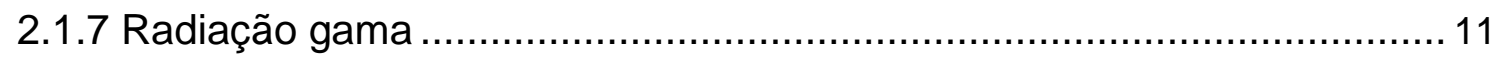

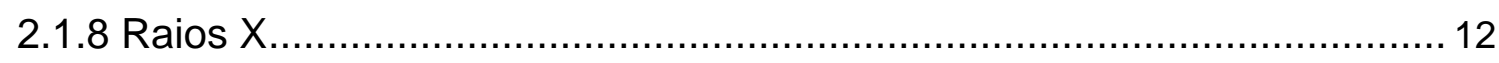

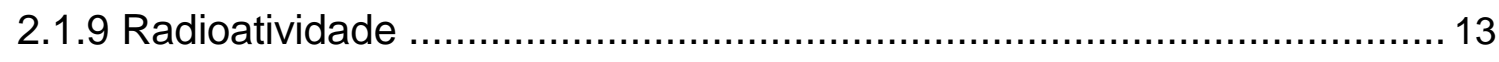

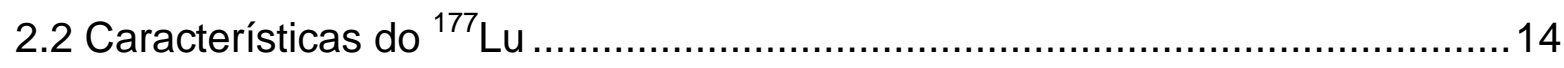

2.2.1 Esquema de desintegração ............................................................. 14

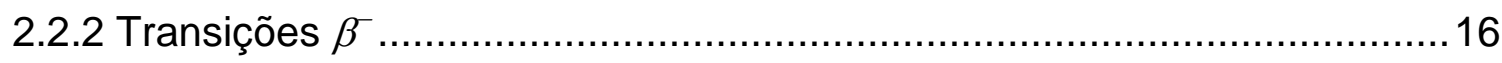




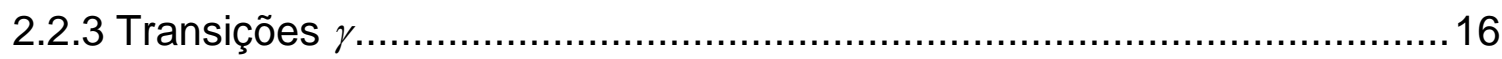

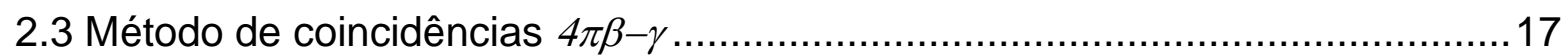

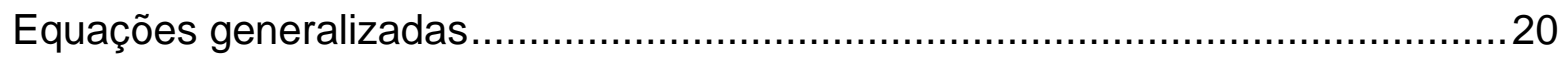

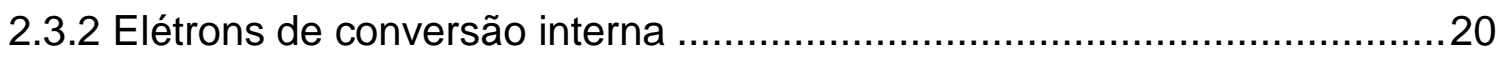

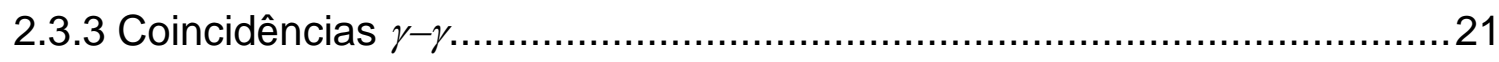

2.3.4 Esquema de desintegração complexo …….......................................22

2.3.5 Técnica da Extrapolação da eficiência................................................26

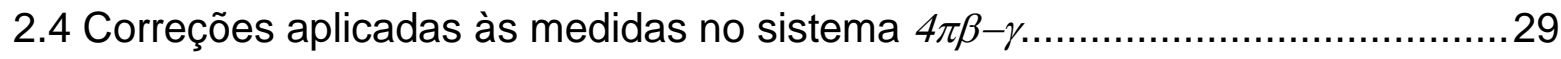

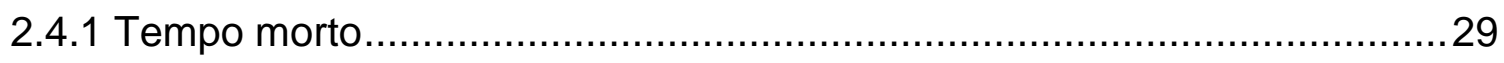

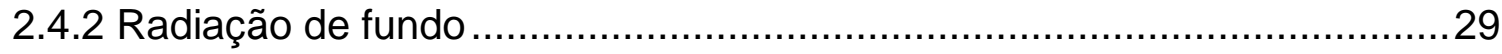

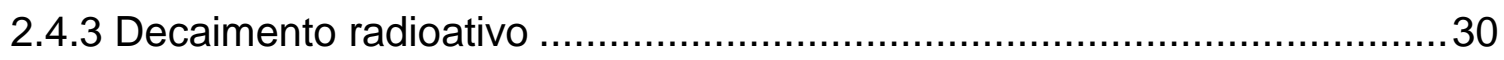

2.4.4 Correção para coincidências acidentais.................................................30

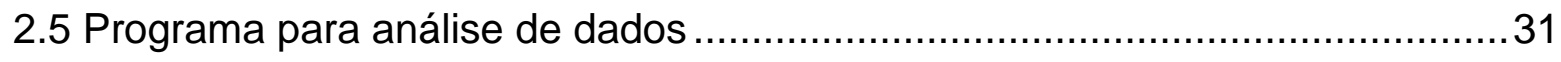

2.6 Determinação da probabilidade de emissão gama por decaimento ..................31

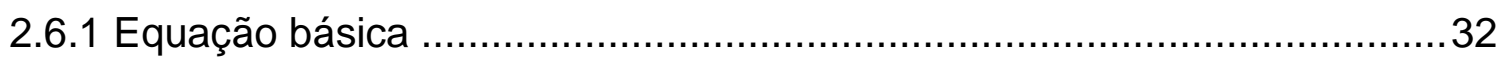

2.6.2 Curva de eficiência do espectrômetro gama..........................................33

2.6.3 Correções aplicadas ...................................................................... 33

2.6.3.1 Correção para tempo morto, radiação de fundo e decaimento

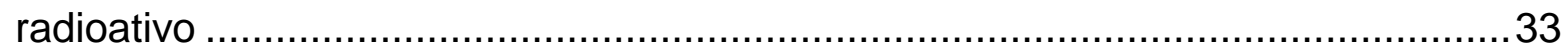

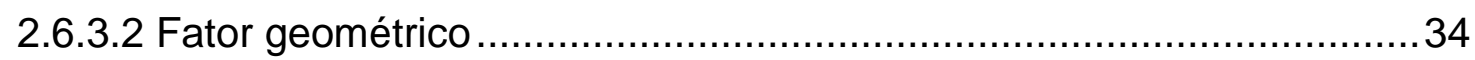

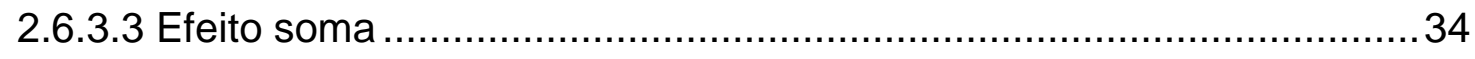

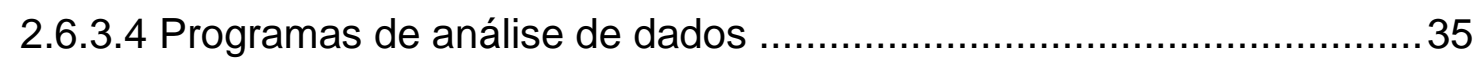




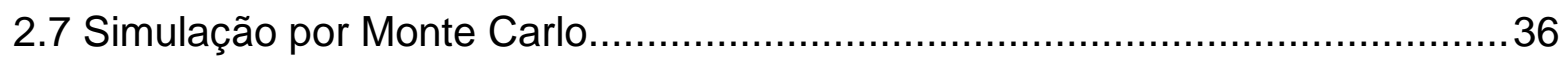

2.7.1 Cálculo das funções de resposta dos detectores do sistema $4 \pi \beta-\gamma \ldots \ldots \ldots .36$

2.7.2 Simulação do esquema de desintegração ..............................................38

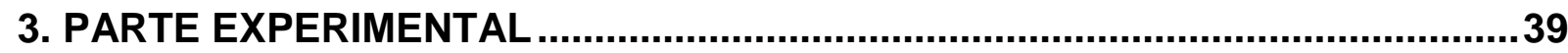

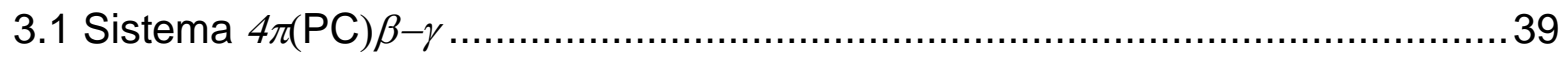

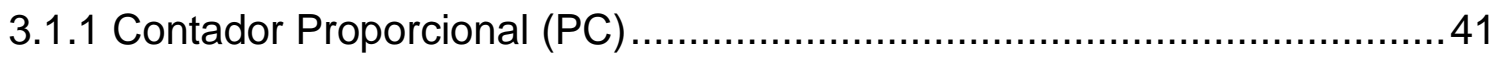

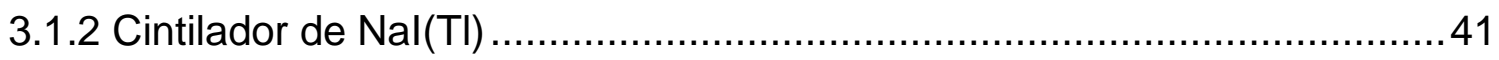

3.1.3 Arranjo do sistema eletrônico........................................................... 43

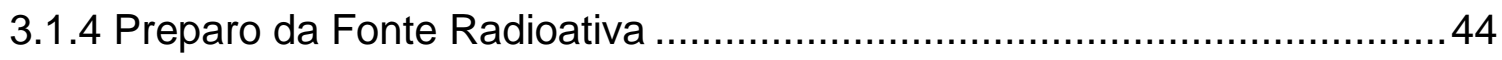

3.1.5 Variação da eficiência beta ............................................................. 45

3.2 Espectrômetro gama com detector HPGe ................................................. 45

3.2.1 Medida da probabilidade de emissão gama das transições de 113 e 208

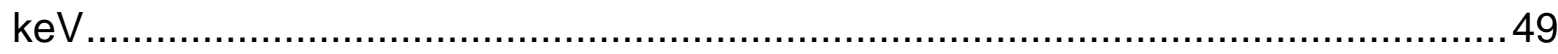

3.2.2 Medida da probabilidade de emissão gama das transições de 136 e 249

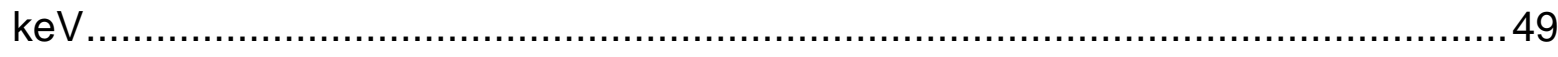

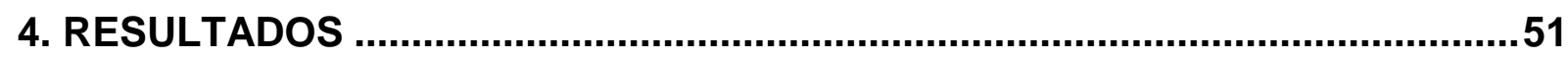

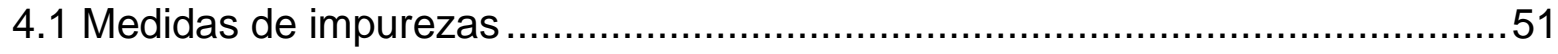

4.2 Comparação dos espectros experimental e teórico do detector de $\mathrm{Nal}(\mathrm{TI})$.......52

4.3 Curva de extrapolação da eficiência .........................................................53

4.4 Interpolação dos dados experimentais com os valores obtidos pela simulação. 
4.5 Obtenção da curva de eficiência em função da energia gama 63 4.6 Medida da probabilidade de emissão gama das transições gama (113 e 208 $\mathrm{keV})$ 65

4.7 Medida da probabilidade de emissão gama das transições gama (136 e 249 $\mathrm{keV})$ 68

5. CONCLUSÕES. .71 REFERÊNCIAS BIBLIOGRÁFICAS. .72 


\section{LISTA DE FIGURAS}

\section{Páginas}

Figura 2.1: Relação entre massa do núcleo e número atômico para um dado número de massa $A$.

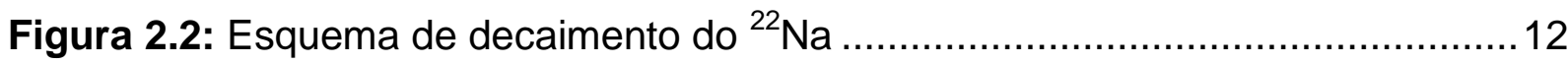

Figura 2.3: Esquema de decaimento do ${ }^{177} \mathrm{Lu}$................................................... 15

Figura 2.4: Exemplo de um esquema de desintegração simples .............................18

Figura 2.5: Esquema de desintegração com quatro ramos beta..............................2 23

Figura 2.6: Representação detalhada da situação experimental utilizada para a

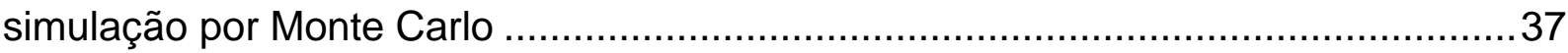

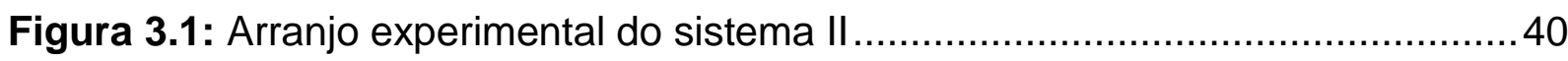

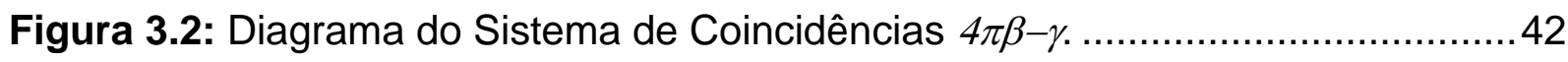

Figura 3.3: Fotografia do sistema de medidas do HPGe. ...................................4 47

Figura 3.4: Diagrama do sistema eletrônico associado ao HPGe ............................48

Figura 4.1: Espectro gama obtido pelo detector HPGe......................................51

Figura 4.2: Espectro gama obtido pelo detector $\mathrm{Nal}(\mathrm{TI})$ do sistema de coincidência.

Figura 4.3: Ajuste de reta e extrapolação para o valor de ineficiência igual a zero com base nos dados obtidos para a janela gama de $113 \mathrm{keV}$.

Figura 4.4: Ajuste de reta e extrapolação para o valor de ineficiência igual a zero com base nos dados obtidos para a janela gama de $208 \mathrm{keV}$..............................5

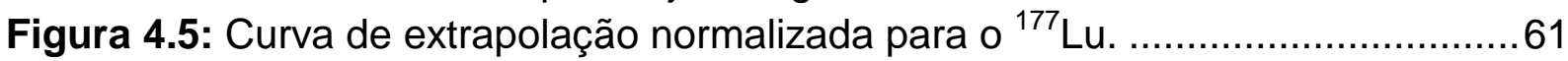

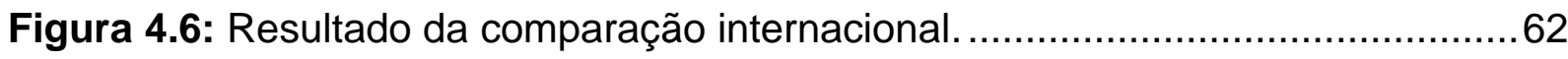

Figura 4.7 : Curva de eficiência de pico em função da energia gama, para o espectrômetro de HPGe.

Figura 4.8: Resíduos percentuais entre os valores de eficiência ajustados e experimentais em função da energia gama, para o detector de HPGe 


\section{LISTA DE TABELAS}

Páginas

Tabela 2.1: Transições $\beta$-: Energias máxima e média da partícula $\beta$. 16

Tabela 2.2: Energia da radiação gama juntamente com a respectiva intensidade

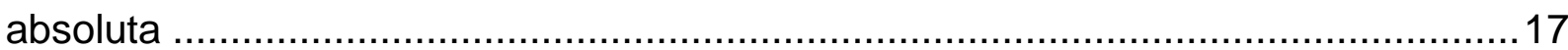

Tabela 4.1 : Variação do parâmetro de ineficiência .54

Tabela 4.2: Incertezas parciais associadas à medida de atividade da fonte 14331 para a janela gama de $113 \mathrm{keV}$ (em percentagem)

Tabela 4.3: Incertezas parciais associadas à medida de atividade da fonte 14331 para a janela gama de $208 \mathrm{keV}$ (em percentagem).

Tabela 4.4: Dados das demais fontes medidas, para a janela gama de $113 \mathrm{KeV}$.....58

Tabela 4.5: Dados das demais fontes medidas, para a janela gama de $208 \mathrm{KeV}$....59

Tabela 4.6: Incertezas parciais associadas à medida de atividade das demais fontes, para a janela gama de $113 \mathrm{keV}$

Tabela 4.7: Incertezas parciais associadas à medida de atividade das demais fontes, para a janela gama de $208 \mathrm{keV}$.

Tabela 4.8: Parâmetros e matriz de covariância obtidos pelo ajuste da curva de eficiência do HPGe 64

Tabela 4.9: Probabilidade de emissão gama por decaimento do ${ }^{177} \mathrm{Lu}$, juntamente com a matriz de covariância correspondente.

Tabela 4.10: Quadro de incertezas..

Tabela 4.11: Média dos valores de probabilidades de emissão obtidos para cada uma das 7 fontes de ${ }^{177} \mathrm{Lu}$, tomando como referência a intensidade da transição de $208 \mathrm{keV}$. 68

Tabela 4.12: Média dos valores obtidos para cada uma das 7 fontes, tomando como referência a intensidade da transição de $113 \mathrm{keV}$ 69

Tabela 4.13 Probabilidades de emissão gama por decaimento finais para $0{ }^{177} \mathrm{Lu}$ para as transições menos intensas. 


\section{INTRODUÇÃO}

A escolha do radionuclídeo ${ }^{177}$ Lu para este trabalho se deve à importância que este radionuclídeo vem ganhando em Medicina Nuclear ${ }^{[1]}$. Este radionuclídeo possui meia vida de 6,6 dias e decai por emissão de partículas $\beta$, populando os estados excitados do ${ }^{177} \mathrm{Hf}$ que, por sua vez, emite radiação gama durante 0 processo de desexcitação.

Por apresentar energias beta máxima e média de 421 e 133 keV, respectivamente, sua utilização se torna muito conveniente em Medicina Nuclear, uma vez que resulta em uma baixa dose de radiação beta no tecido. Além disso, o ${ }^{177} \mathrm{Lu}$ emite radiação gama de baixa energia, sendo de $113 \mathrm{keV}$ e $208 \mathrm{keV}$ as energias dos fótons gama de maior intensidade, o que permite uma aquisição de imagens enquanto ocorre o tratamento. Outra característica vantajosa é sua meiavida considerada longa pela medicina nuclear, mas que permite cobrir a distância entre o hospital e o reator nuclear, onde ele é produzido ${ }^{[1]}$.

Estudos recentes têm demonstrado a eficácia do ${ }^{177} \mathrm{Lu}$ no tratamento de câncer neuroendócrino, apresentando resultados melhores que outros radionuclídeos que vinham sendo utilizados para este fim, tais como $\circ{ }^{111}$ In e $\circ{ }^{90} \mathrm{Y}$. Neste tratamento, o ${ }^{177} \mathrm{Lu}$ é utilizado para marcar a somatostatina, resultando em ${ }^{177} \mathrm{Lu}$ Tyr3-octreotato $\left({ }^{177}\right.$ Lu-DOTATATE $){ }^{[1]}$. Outra aplicação importante do ${ }^{177}$ Lu é no tratamento paliativo para pacientes com dores ósseas. Neste caso o ${ }^{177} \mathrm{Lu}$ é utilizado na marcação do etilenodiaminotetrametilfosfato (EDTPM) formando então o ${ }^{177} \mathrm{Lu}$ EDTPM ${ }^{[1]}$.

O conhecimento da atividade específica do ${ }^{177}$ Lu com grande exatidão é de extrema importância para a produção de um padrão primário, o que pode ser obtido pelo método de coincidências $4 \pi \beta-\gamma$. Da mesma forma, o conhecimento das 
probabilidades de emissão gama absolutas (ou probabilidade de emissão gama por decaimento) é importante para uma calibração secundária, normalmente efetuada por meio de espectrômetros gama ou câmaras de ionização de poço.

A literatura apresenta poucos trabalhos, tanto com relação ao desenvolvimento da metodologia para a determinação da atividade, quanto para a medida absoluta das intensidades gama, especialmente para as transições de menor intensidade.

\subsection{Objetivos}

O presente trabalho tem como objetivo apresentar detalhadamente a metodologia utilizada na determinação absoluta da atividade do ${ }^{177} \mathrm{Lu}$, bem como a utilizada na determinação das probabilidades de emissão gama por decaimento. Além disto, pretende-se apresentar os resultados obtidos por meio da simulação por Monte Carlo, que pode reproduzir a situação experimental do sistema de coincidências $4 \pi \beta-\gamma$, antes da realização do experimento.

No capítulo 2 são apresentados os fundamentos teóricos que descrevem os fenômenos nucleares de interesse neste trabalho. Também são apresentadas as características do ${ }^{177} \mathrm{Lu}$ além da metodologia utilizada, incluindo o método de coincidências $4 \pi \beta-\gamma$ e o método de medida das probabilidade de emissão gama por decaimento.

No capítulo 3 é feita uma descrição da parte experimental, apresentando detalhes do sistema de medidas do método de coincidências e do espectrômetro gama.

No capítulo 4 são apresentados e analisados os resultados obtidos tanto experimentalmente como por meio da simulação pelo método de Monte Carlo.

No capítulo 5 estão as conclusões deste trabalho e propostas para trabalhos futuros. 


\section{FUNDAMENTOS TEÓRICOS}

\subsection{Desintegração nuclear}

Para um determinado número de nucleons em um núcleo atômico, existe um nível de energia que é o mais baixo possível. Quando um núcleo atômico não se encontra neste nível mais baixo ele se encontra em um estado instável e possui a tendência de emitir algum tipo de radiação. ${ }^{[2]}$

Pode-se dividir os diferentes tipos de radiação emitida por núcleos instáveis em 4 grupos: ${ }^{[2][3]}$

- Elétrons $\left(\beta^{+}, \beta\right.$, elétrons Auger e elétrons de conversão interna);

- Partículas carregadas pesadas;

- Radiação eletromagnética;

- Nêutrons.

Os dois primeiros grupos mencionados acima são compostos por partículas carregadas e os dois últimos grupos são compostos por radiações sem carga. Os elétrons podem se originar em um processo de desintegração nuclear chamado de decaimento $\beta$, que ocorre porque o número atômico $Z$, levando-se em conta a massa atômica, não corresponde à menor energia possível. Este decaimento pode ocorrer de três formas diferentes: Decaimento $\beta^{-}$, decaimento $\beta^{+}$e captura eletrônica. Outra forma de se obter elétrons é através do processo de conversão interna ou emissão de elétrons Auger. O grupo das partículas pesadas carregadas abrange todas as partículas com número atômico igual ou maior a uma unidade de massa atômica, como os prótons, as partículas alfa, e os produtos de reações 
nucleares. Assim como a radiação beta a radiação alfa também é gerada por um processo de desintegração nuclear, chamado de decaimento alfa, que normalmente ocorre em núcleos com número atômico superior a 82 . As radiações eletromagnéticas de origem nuclear ou atômica, de interesse neste trabalho são os raios- $X$, produzidos pela transição de elétrons entre as camadas atômicas e os raiosgama, resultantes da desexcitação do núcleo atômico. Os nêutrons são gerados em diferentes reações nucleares como na fissão nuclear, por exemplo.

\subsubsection{Decaimento $\beta$}

É o processo no qual um núcleo de número atômico $Z$ e número de massa $A$ emite um elétron (carga negativa), passando a ter um número atômico $Z+1$ e 0 mesmo número de massa $A$. A emissão de um elétron nuclear ocorre porque um nêutron $(n)$ se converte em um próton $(p)$ emitindo uma partícula $\beta^{-}$e um antineutrino $(\bar{v})$. Desta forma, $Z$ aumenta de uma unidade e o número de nêutrons $(N)$ diminui também de uma unidade, o que justifica o fato de $A$ permanecer inalterado. A equação abaixo descreve o processo de emissão da partícula $\beta$ :

$$
n \rightarrow p+\beta^{-}+\bar{v}
$$

Esquematicamente, o decaimento $\beta^{-}$pode ser representado da seguinte maneira:

$$
{ }_{Z}^{A} X \rightarrow{ }_{Z+1}^{A} Y+\beta^{-}+\bar{v}
$$

Onde $X$ é o núcleo pai com número de massa $A$ e número atômico $Z$, e $Y$ é o núcleo filho com o mesmo número de massa e número atômico aumentado de uma unidade. 
A desintegração $\beta$ é caracterizada por uma energia fixa de decaimento $(Q)$ que corresponde à diferença entre o nível de energia do núcleo instável e o nível de energia em que o núcleo se encontra após a desintegração. Esta energia é repartida entre a partícula $\beta$ e o antineutrino, de forma que a energia da partícula $\beta$ não é fixa, podendo variar de zero (caso em que $\mathrm{o}$ antineutrino adquire toda a energia de desintegração) a $Q$ (caso em que 0 antineutrino não adquire nenhuma energia). Quando se tem um grande número de transições as energias assumidas pelas partículas beta resultarão em um espectro contínuo de energia variando de 0 a um valor máximo dado por:

$$
Q_{i}=\left[M_{X}-M_{Y}\right] c^{2}-E_{i}
$$

Onde

$Q_{i}$ é a energia liberada na desintegração para o nível de energia $E_{i}$. Quando o estado final é o nível fundamental do núcleo filho, então $E_{i}=0$ e $Q_{i}=Q$;

Mx é a massa do núcleo pai;

MY é a massa do núcleo filho;

$c$ é velocidade da luz;

$E_{i}$ é a energia do nível para o qual ocorre a desintegração.

A energia média da partícula $\beta$ é dada por:

$$
E_{m e ́ d}=\frac{\int_{0}^{E_{m a ́ x}} E N(E) d E}{\int_{0}^{E_{m a ́ x}} N(E) d E}
$$


Nem sempre a desintegração garante que núcleo atinja o estado de menor energia possível, de modo que o núcleo filho pode ocupar um estado excitado. Esta desexcitação ocorre usualmente por meio da emissão de uma radiação gama. Este fenômeno torna possível o método de coincidências $\beta-\gamma$, o qual será explicado mais adiante.

\subsubsection{Decaimento $\beta^{+}$}

É um fenômeno semelhante ao decaimento $\beta$, porém neste caso é o próton que se transforma em um nêutron através da emissão de um elétron positivo:

$$
p \rightarrow n+\beta^{+}+v
$$

Neste caso, ao contrário do que ocorre no decaimento $\beta$, o número atômico diminui de uma unidade. Esquematicamente o decaimento $\beta^{+}$pode ser representado da seguinte forma:

$$
{ }_{Z}^{A} X \rightarrow{ }_{Z-1}^{A} Y+\beta^{+}+v
$$

A energia liberada no decaimento $\beta^{+}$é dada pela equação (2.7):

$$
Q_{i}=\left[M_{X}-M_{Y}-2 m\right] c^{2}-E_{i}
$$


Onde $m$ é a massa do elétron.

Quando ocorre emissão de pósitron o átomo também precisará emitir um elétron, uma vez que sua carga positiva será diminuída de uma unidade. Neste caso a compensação das massas de elétrons, encontrada nos outros processos, não ocorre. Desta forma, para que a reação ocorra a massa do núcleo pai precisa ser maior que o núcleo filho mais duas massas de repouso de um elétron, o que explica por que este processo é mais raro que os demais.

O gráfico 1 mostra a relação entre a massa do núcleo (em unidades de energia) para um dado número de massa (neste caso 135) em função do número atômico.

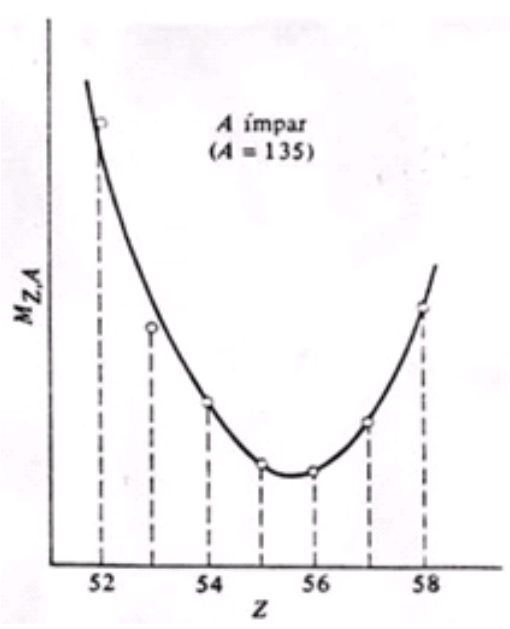

FIGURA 2.1: Relação entre massa do núcleo e número atômico para um dado número de massa $A^{[2]}$.

O núcleo tende a assumir o número atômico $Z$ que corresponde ao mínimo da parábola. Caso o núcleo possua $Z$ maior do que o correspondente ao mínimo da parábola, ele se desintegra por decaimento $\beta^{+}$. Entretanto, se o núcleo apresentar $Z$ menor do que o que corresponde ao mínimo da parábola ele se desintegra por decaimento $\beta$. 
A energia assumida pela partícula $\beta^{+}$, assim como no caso da partícula $\beta$, também dá origem a um espectro contínuo, uma vez que a energia de decaimento pode ser repartida entre a partícula $\beta^{+}$e o neutrino.

\subsubsection{Captura eletrônica}

Ocorre quando a soma da massa inicial do núcleo com a massa de repouso do elétron é menor do que a massa final. Este processo pode ser entendido como o inverso dos dois casos anteriores, pois em lugar de emitir uma partícula $\beta^{+} 0$ núcleo captura um elétron orbital promovendo a seguinte reação:

$$
p+e^{-} \rightarrow n+v
$$

Um próton converte-se em um nêutron após combinar-se com o elétron orbital capturado. Nesta reação um neutrino é emitido. O número atômico diminui uma unidade e o número de massa não se altera, conforme é mostrado na equação 2.8:

$$
{ }_{Z}^{A} X+e^{-} \rightarrow{ }_{Z-1}^{A} Y+v
$$

A energia liberada no decaimento é devida à diferença de massa entre o núcleo pai e o núcleo filho, como a liberada pela emissão de partícula $\beta$-, e é dada pela equação (2.3). 


\subsubsection{Elétrons de conversão interna}

Conforme mencionado anteriormente, após o decaimento $\beta$ o núcleo filho pode não atingir o estado fundamental (nível mais baixo de energia), desexcitandose normalmente por meio da emissão de um fóton gama. Entretanto, esta energia que seria transportada pelo fóton pode ser alternativamente transferida integralmente para um elétron orbital, denominado elétron de conversão interna. Neste caso, a energia do elétron é dada por:

$$
E_{e-}=E_{e x}-E_{l}
$$

$\mathrm{Na}$ qual,

$E_{e-}$ é a energia adquirida pelo elétron;

$E_{e x}$ é a energia de desexcitação;

$E_{l}$ é a energia de ligação relativa à camada ocupada pelo elétron.

Diferentemente dos elétrons originários do decaimento $\beta$, os elétrons de conversão interna apresentam um espectro discreto de energia. Uma única energia de desexcitação pode dar origem a elétrons de diferentes energias, uma vez que pode ser transmitida a elétrons com diferentes valores de $E_{/}$. $O$ espectro de energias assumidas pelos elétrons de conversão interna pode ser ainda mais variado, considerando que o núcleo filho pode apresentar mais de um nível excitado, resultando em diferentes valores de $E_{e x}$.

\subsubsection{Elétrons Auger}

Este é um fenômeno análogo à conversão interna, mas neste caso a energia transferida ao elétron provém da transição entre dois níveis atômicos (camadas eletrônicas) de energia. Por meio de algum processo anterior (como por 
exemplo a captura eletrônica) uma vacância é criada em uma das camadas do átomo. Esta vacância é preenchida por um elétron proveniente de uma camada de maior energia. A diferença de energia entre as camadas é liberada normalmente na forma de um fóton de raios- $X$ característico mas, em alguns casos, esta diferença de energia pode ser transferida diretamente para um elétron de uma das camadas eletrônicas fazendo com que o elétron seja ejetado do átomo com energia igual à diferença entre a energia de transição entre as camadas e a energia de ligação do elétron.

Normalmente, as energias dos elétrons Auger são muito baixas se comparadas às energias das partículas $\beta$ ou às energias dos elétrons de conversão interna, porque os elétrons Auger ocorrem mais freqüentemente em elementos com $Z$ baixo, o que implica em energias de ligação também baixas, da ordem de poucos keV. Com energias tão baixas os elétrons Auger podem ser auto-absorvidos no substrato da fonte radioativa ou barrados pela janela de entrada dos detectores.

\subsubsection{Radiação Alfa}

O núcleo emite uma partícula com número atômico $Z=2$ e número de massa $A=4$ resultando em um núcleo filho com as características mostradas no esquema abaixo:

$$
{ }_{Z}^{A} X \rightarrow{ }_{Z-2}^{A-4} Y+{ }_{2}^{4} \alpha
$$

Este fenômeno ocorre espontaneamente por que a massa do núcleo filho somada à massa da partícula $\alpha$ é menor do que a massa do núcleo pai. A redução da massa nuclear é basicamente causada pela redução da energia coulombiana do 
núcleo, quando sua carga é diminuída de $2 e$. A energia equivalente à diferença de massa aparece sob forma de energia cinética da partícula $\alpha$ e de recuo do núcleo filho, dada por:

$$
E=\left[M_{X}-\left(M_{Y}+M_{\alpha)}\right] c^{2}\right.
$$

$\mathrm{Na}$ qual,

$E$ é a energia de decaimento, transportada pela partícula $\alpha$ sob a forma de energia cinética;

$M_{x}$ é a massa do núcleo pai;

$M_{y}$ é a massa do núcleo filho;

$M_{\alpha}$ é a massa da partícula $\alpha$.

Um fato que chama atenção é o de que a energia cinética da partícula $\alpha$ é menor do que o potencial coulombiano atrativo do núcleo, o que deveria impedir que a partícula se desligasse do núcleo. O que explica a emissão é o efeito túnel, ou penetração de barreira. Quanto maior for a espessura da barreira em relação à energia da partícula $\alpha$, menor será a probabilidade de emissão.

\subsubsection{Radiação gama}

Em vários casos, quando ocorre o processo de desintegração, o núcleo filho é produzido em um de seus níveis de excitação. Este excesso de energia pode ser liberado na forma de radiação eletromagnética, denominada raios gama. A figura (2.2) mostra o esquema de decaimento do ${ }^{22} \mathrm{Na}$, que se desintegra por emissão de uma partícula $\beta^{+}$, populando o estado excitado do ${ }^{22} \mathrm{Ne}$, seguido de emissão gama. 


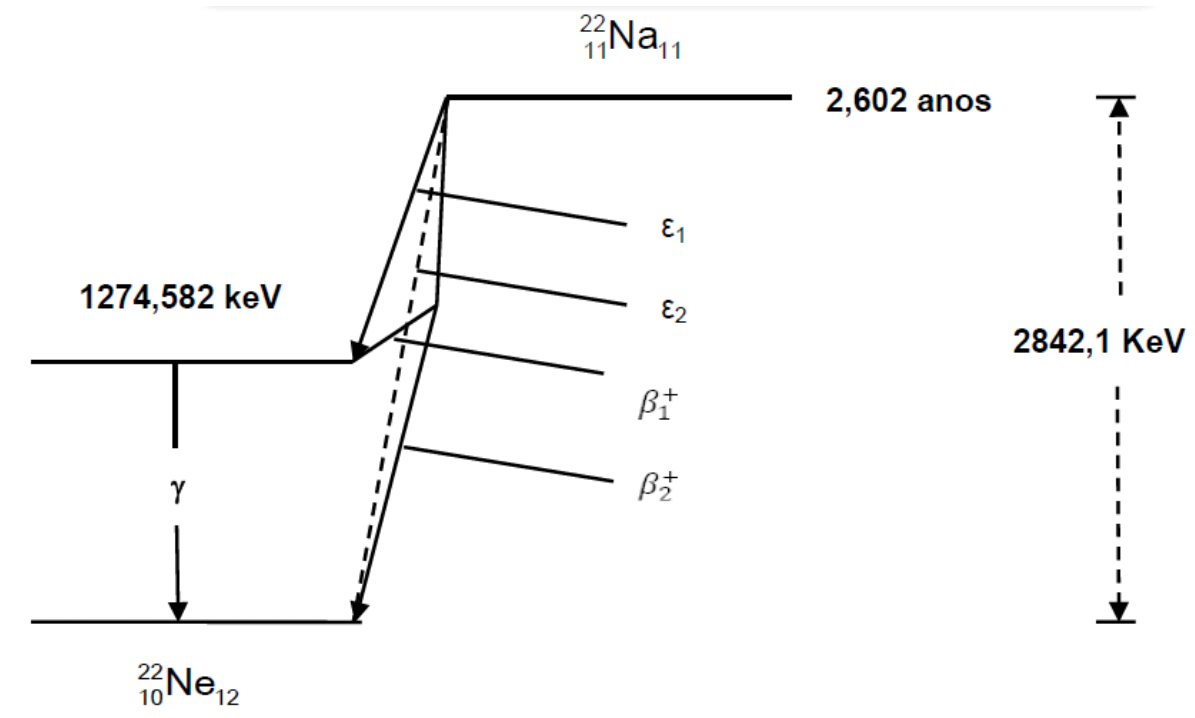

FIGURA 2.2: Esquema de decaimento do ${ }^{22} \mathrm{Na}$ que pode se desintegrar tanto por $\beta^{+}$ quanto por captura eletrônica. No caso da emissão $\beta^{+}$, também haverá a emissão de dois fótons de $0,511 \mathrm{MeV}^{[2]}$.

A energia transportada pelo fóton de radiação gama é característica do núcleo filho, pois os estados excitados do núcleo são bem definidos.

Outra maneira de se obter fótons é por meio da aniquilação de pares, fenômeno no qual uma partícula e uma antipartícula, normalmente um elétron atômico e um pósitron proveniente de um decaimento $\beta^{+}$, se encontram. Ambas as partículas desaparecem e dão lugar a dois fótons, movendo-se em direções opostas, cada um com energia de $0,511 \mathrm{MeV}$. No caso do ${ }^{22} \mathrm{Na}$, na figura (2.2), tanto são emitidos fótons de 1,274 MeV como de $0,511 \mathrm{MeV}$, sendo os últimos resultantes da aniquilação de pares.

\subsubsection{Raios X}

Quanto à origem, os fótons de raios-X podem ser divididos em dois grupos: raios-X característicos e raios- $X$ gerados por bremsstrahlung. 
Os raios-X característicos são provenientes de transições de elétrons entre as camadas atômicas. Isto pode ocorrer quando uma vacância é criada na camada $K$, por exemplo, e um elétron da camada $L$ preenche esta vacância. $A$ diferença de energia entre as camadas é emitida na forma de um fóton de radiação $X$, que é característico do átomo em questão, uma vez que a diferença de energia entre as camadas é característica. $O$ espectro formado neste processo por sucessivas emissões é discreto, pois os fótons deverão apresentar apenas valores correspondentes às transições entre as camadas.

Bremsstrahlung pode ser entendido como radiação de freamento. Quando um elétron desacelera após interagir com a matéria, parte de sua energia cinética é convertida em radiação $X$. $O$ espectro de energias assumidas pelos fótons neste caso é contínuo tendo como valor máximo o valor da energia cinética inicial do elétron incidente.

\subsubsection{Radioatividade}

Um radioisótopo tem a sua atividade (A) definida pela taxa de desintegração, dada por:

$$
A=-\frac{d N}{d t}=\lambda N
$$

Onde $N$ é o número de núcleos radioativos e $\lambda$ é a constante de desintegração.

A unidade de medida no sistema internacional é o Becquerel (Bq). Esta unidade é definida de forma que $1 \mathrm{~Bq}$ corresponde a 1 desintegração por segundo. 


\subsection{Características do ${ }_{71}^{177} \mathrm{Lu}^{106}$}

Uma vez apresentados os diferentes processos de decaimento e os diversos tipos de radiações possíveis torna-se conveniente uma análise detalhada das características do radionuclídeo de interesse para o presente trabalho, bem como seu esquema de desintegração.

$\mathrm{O}^{177}$ Lu se desintegra por decaimento $\beta$ com uma meia vida de 6,647 (4) $\operatorname{dias}^{[4]}$. O principal modo de produção deste radioisótopo é por meio da reação nuclear ${ }^{176} \mathrm{Lu}(\mathrm{n}, \gamma)^{177} \mathrm{Lu}$, que pode ser produzida em reatores nucleares. O núcleo filho, resultante da desintegração $\beta$, é o ${ }^{177} \mathrm{Hf}$, que pode atingir diretamente o estado fundamental com probabilidade de $79,3 \%$, ou ocupar um dos três possíveis estados excitados (neste caso a desexcitação ocorre por meio da emissão de um fóton de radiação gama ou de um elétron de conversão).

\subsubsection{Esquema de desintegração}

A figura (2.3) mostra o esquema de desintegração do ${ }^{177} \mathrm{Lu}$, incluindo os estados excitados do ${ }^{177} \mathrm{Hf}$. Pelo esquema, nota-se que existem 6 valores de energia que vão de 71 a $321 \mathrm{keV}$, para os fótons de radiação gama, dentre os quais os que ocorrem com maior probabilidade são os que correspondem às transições $\gamma_{3,1}$ (transição entre os níveis $3 \rightarrow 1$ ) e $\gamma_{1,0}$ (transição entre os níveis $1 \rightarrow 0$ ), com valores de 208 e $113 \mathrm{keV}$, respectivamente. 


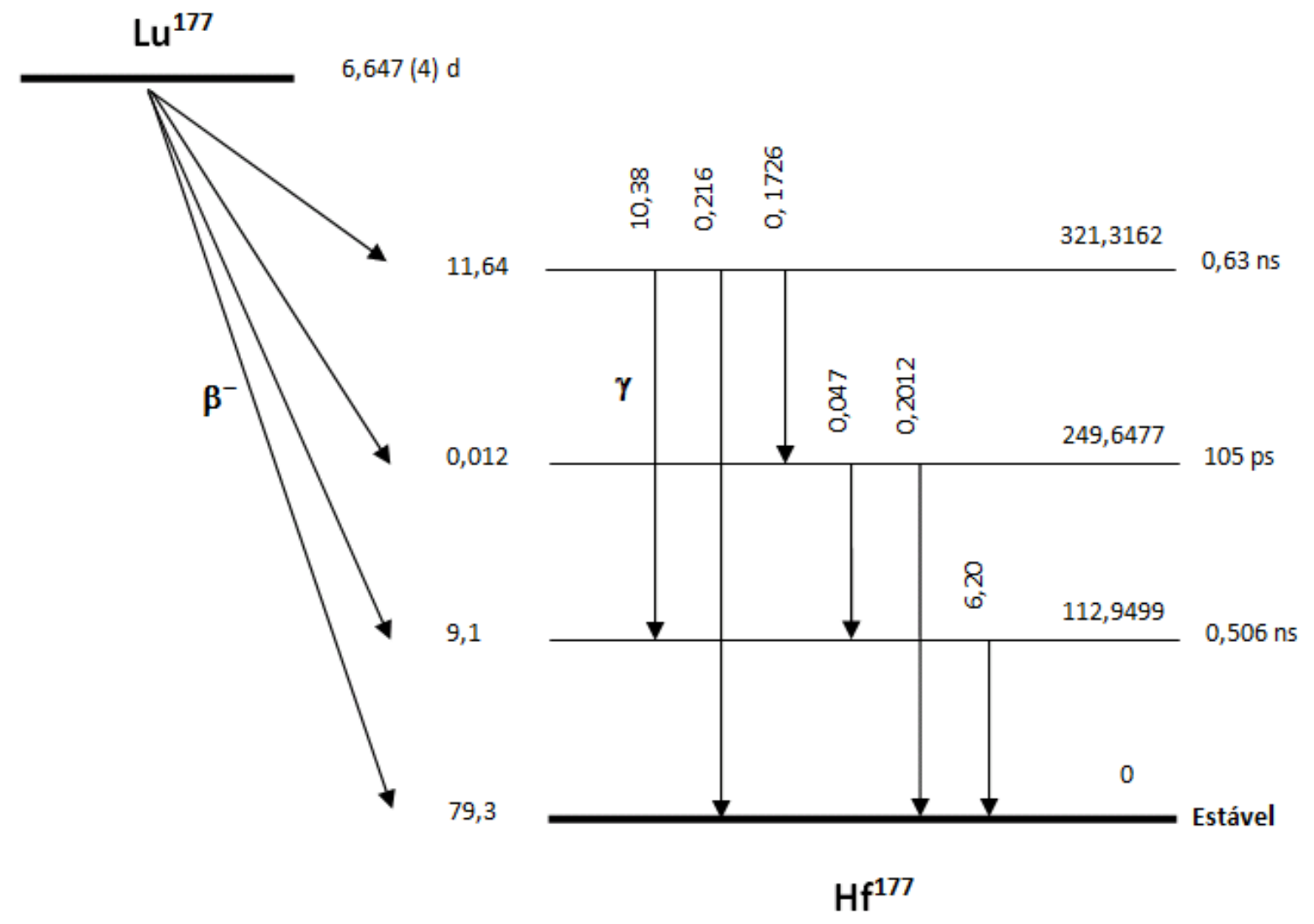

FIGURA 2.3: Esquema de decaimento do ${ }^{177} \mathrm{Lu}{ }^{[4]}$. Os níveis de energia são dados em $\mathrm{keV}$. Os valores acima das transições correspondem às probabilidades de emissão, em porcentagem.

No esquema também são apresentadas as probabilidades para cada um dos quatro ramos beta, sendo que o que ocorre com maior probabilidade é aquele em que o núcleo filho aparece diretamente no estado fundamental, sem a necessidade de desexcitação. Também são mostrados na figura (2.3) os tempos de meia-vida de cada estado excitado.

Nota-se pela figura que a partícula $\beta$ correspondente à transição $\beta_{0,3}^{-}$ (com 11,64\% de probabilidade) está em coincidência com o fóton de $208 \mathrm{keV}$ resultante da transição $\gamma_{3,1}(\mathrm{Hf})$. A partícula $\beta^{-}$proveniente da transição $\beta_{0,1}^{-}$está em coincidência com o fóton de $113 \mathrm{keV}$, correspondente à transição $\gamma_{1,0}\left({ }^{177} \mathrm{Hf}\right)$. 


\subsubsection{Transições $\beta$}

A tabela (2.1) apresenta a energia máxima e a energia média da partícula $\beta$ em cada uma das transições possíveis nas quais o ${ }^{177}$ Lu decai para um dos níveis excitados ou para o estado fundamental do ${ }^{177} \mathrm{Hf}$, juntamente com a probabilidade de cada transição.

TABELA 2.1: Transições $\beta$ : Energias máxima e média da partícula $\beta^{-[4]}$. Os números entre parênteses correspondem à incerteza nos últimos dígitos.

\begin{tabular}{|c|c|c|}
\hline & Energia (keV) & Probabilidade (\%) \\
\hline$\beta_{0,3}^{\top}$ & $\begin{array}{l}\text { máx. } 177,0(8) \\
\text { méd. } \quad 47,66(23)\end{array}$ & $11,64(10)$ \\
\hline$\beta_{0,2}^{-}$ & $\begin{array}{l}\text { máx. 248,6 (8) } \\
\text { méd. 78,6 (3) }\end{array}$ & $0,012(8)$ \\
\hline$\beta_{0,1}{ }_{0,1}$ & $\begin{array}{l}\text { máx. 385,4 (8) } \\
\text { méd. } 111,7 \text { (3) }\end{array}$ & $9,1(5)$ \\
\hline$\beta_{0,0}^{\top}$ & $\begin{array}{l}\text { máx. 498,3 (8) } \\
\text { méd. 149,4 (3) }\end{array}$ & $79,3(5)$ \\
\hline
\end{tabular}

\subsubsection{Transições $\gamma$}

A tabela (2.2) mostra a energia dos fótons emitidos, bem como sua intensidade e o valor do coeficiente de conversão interna. 
TABELA 2.2: Energia da radiação gama juntamente com a respectiva intensidade absoluta. O coeficiente de conversão interna indica a possibilidade da energia da radiação gama dar origem a um elétron de conversão ${ }^{[4]}$.

\begin{tabular}{lccc}
\hline & Energia (keV) & $\begin{array}{r}\text { Fótons por 100 } \\
\text { desintegrações }\end{array}$ & $\begin{array}{c}\text { Coeficiente de } \\
\text { conversão interna total } \\
\left(\alpha_{T}\right)\end{array}$ \\
\hline$\gamma_{3,2}(\mathbf{H f})$ & $71,6418(6)$ & $0,1726(23)$ & $0,894(22)$ \\
$\gamma_{1,0}(\mathbf{H f})$ & $112,9498(4)$ & $6,20(7)$ & $2,272(5)$ \\
$\gamma_{2,1}(\mathbf{H f})$ & $136,7245(5)$ & $0,0470(7)$ & $1,158(18)$ \\
$\gamma_{3,1}(\mathbf{H f})$ & $208,3662(4)$ & $10,38(7)$ & $0,068(5)$ \\
$\gamma_{2,0}(\mathbf{H f})$ & $249,6742(6)$ & $0,2012(21)$ & 0,141 \\
$\gamma_{3,0}(\mathbf{H f})$ & $321,3159(6)$ & $0,216(8)$ & $0,08(6)$ \\
\hline
\end{tabular}

\subsection{Método de Coincidências $4 \pi \beta-\gamma$}

O método de coincidências $4 \pi \beta-\gamma$ constitui uma técnica primária de determinação da atividade específica e é amplamente utilizado, em razão do seu alto grau de exatidão ${ }^{[5-14]}$, sendo adequado para a produção de padrões de radionuclídeos. No Laboratório de Metrologia Nuclear (LMN) do IPEN-CNEN/SP ele é utilizado desde 1967 e, ao longo deste tempo, foi passando por diversos aprimoramentos, o que tem possibilitado uma melhoria na exatidão, principalmente para radionuclídeos com esquemas de desintegração complexos ${ }^{[15-18]}$.

Recentemente, um novo sistema de aquisição de dados (denominado "coincidência por software") está sendo implementado no LMN $^{[19]}$ e deverá substituir 
o sistema tradicional. Neste sistema, em lugar de utilizarem-se dispositivos eletrônicos para discriminação dos pulsos e ajustes de amplificação e tempo, os pulsos amplificados são processados por uma placa de aquisição e enviados diretamente ao computador. Desta forma, os pulsos das vias beta e gama poderão ser analisados a posteriori, identificando-se as coincidências para qualquer nível de discriminação gama, o que facilitará bastante a análise e diminuirá significativamente o tempo despendido com as medidas.

O método de coincidências se baseia na deteç̧ão de radiações consideradas coincidentes, isto é, que são emitidas em um intervalo menor que a resolução em tempo do sistema de medidas. Quando um núcleo se desintegra, por exemplo, por emissão beta, o núcleo filho pode ser formado no estado fundamental ou em um de seus estados excitados. Caso seja formado em um estado excitado, ele irá se desexcitar emitindo uma radiação gama (ou um elétron de conversão interna) que, em muitos casos, pode ser considerado coincidente com a emissão beta. A figura (2.4) apresenta uma situação na qual o elemento se desintegra por decaimento beta e se desexcita emitindo uma radiação gama.

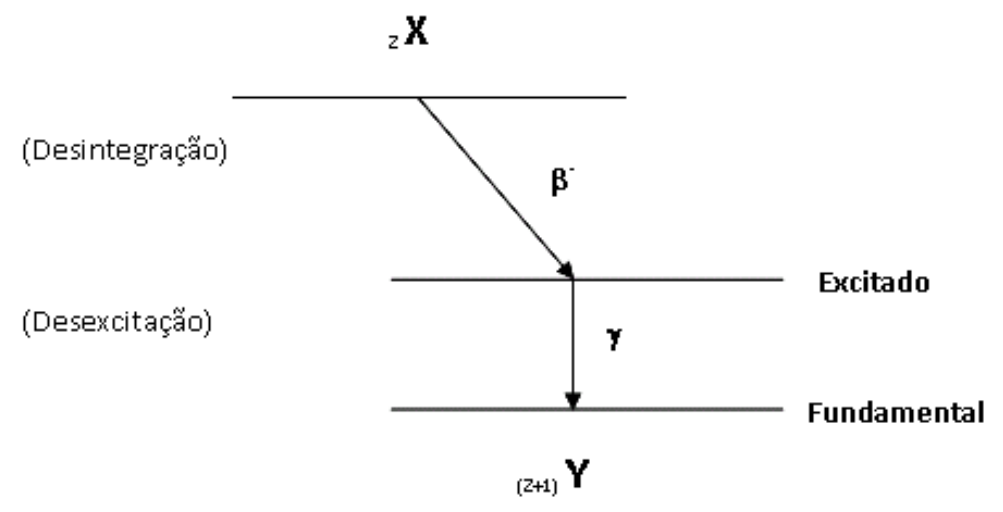

FIGURA 2.4: Exemplo de um esquema de desintegração simples. O fóton de radiação gama é emitido logo depois de uma desintegração beta para a desexcitação do átomo. 
Para este esquema de desintegração simples e considerando detectores sensíveis à apenas um tipo de radiação, os números de contagens registradas pelos detectores beta $\left(N_{\beta}\right)$, gama $\left(N_{\gamma}\right)$ e por meio de um módulo de coincidência $\left(N_{c}\right)$, podem ser dados respectivamente por:

$$
\begin{aligned}
& N_{\beta}=N_{0} \varepsilon_{\beta} \\
& N_{\gamma}=N_{0} \varepsilon_{\gamma} \\
& N_{c}=N_{0} \varepsilon_{\beta} \varepsilon_{\gamma} \\
& \varepsilon_{\beta}=\frac{N_{c}}{N_{\gamma}}
\end{aligned}
$$

Onde:

$N_{0}$ é a atividade da fonte;

$\varepsilon_{\beta}$ é a eficiência do detector beta e

$\varepsilon_{\gamma}$ é a eficiência do detector gama.

Se multiplicarmos as equações (2.14) por (2.15) e dividirmos por (2.16) teremos:

$$
\frac{N_{\beta} N_{\gamma}}{N_{c}}=N_{0}
$$


Como se pode observar na equação (2.18), a atividade $\left(N_{0}\right)$ pode ser obtida sem a necessidade do conhecimento prévio dos parâmetros de desintegração do elemento, nem das eficiências dos detectores, quando o esquema de desintegração é simples.

\subsubsection{Equações Generalizadas}

Nos casos reais, torna-se necessário que se leve em conta diversos fatores, como por exemplo, a possibilidade do detector beta detectar a radiação gama (este problema normalmente não ocorre com o detector gama, pois, como a radiação beta é pouco penetrante, não consegue atravessar a janela do detector de radiação gama ${ }^{[6]}$. Também é necessário observar que o sistema de detecção beta (via beta) pode apresentar um tempo de resposta diferente do apresentado pelo sistema de detecção gama (via gama). Além disso, deve-se levar em conta a geometria da fonte radioativa, tomada como puntiforme no caso ideal, e o fato de o detector apresentar eficiências diferentes em regiões diferentes da fonte.

Deste modo, as equações apresentadas anteriormente, acabam ganhando uma complexidade bem maior. Abaixo, estas considerações são aplicadas às equações, de modo a torná-las adequadas para um caso não ideal ${ }^{[6,10,16,20]}$.

\subsubsection{Elétrons de Conversão Interna $(\mathrm{Cl})^{[6]}$}

Uma vez que a eficiência do detector beta não é de $100 \%$, ele pode, no caso de não detectar uma partícula beta, registrar um elétron de conversão proveniente da transição gama em coincidência. Neste caso obtemos: 


$$
N_{\beta}=N_{0}\left[\varepsilon_{\beta}+\left(1-\varepsilon_{\beta}\right) \frac{\alpha}{1+\alpha} \varepsilon_{C I}\right]
$$

Onde: $\alpha$ é o coeficiente de conversão interna e $\varepsilon_{c i}$ é a probabilidade de se detectar um elétron de conversão no detector beta.

Assim, temos:

$$
\frac{N_{\beta} N_{\gamma}}{N_{c}}=N_{0}\left[1+\frac{\left(1-\varepsilon_{\beta}\right)}{\varepsilon_{\beta}} \frac{\alpha}{1+\alpha} \varepsilon_{C I}\right]
$$

\subsubsection{Coincidências $\gamma-\gamma^{[6]}$}

Os detectores de radiação $\beta$ eventualmente podem registrar radiações gama. Caso o isótopo apresente um esquema de desintegração no qual um único fóton de radiação gama seja emitido após a desintegração beta, não será registrada a coincidência e a correção fica bastante simples, como se pode ver na equação 2.20:

$$
\frac{N_{\beta} N_{\gamma}}{N_{c}}=N_{0}\left[1+\frac{\left(1-\varepsilon_{\beta}\right)}{\varepsilon_{\beta}}\left(\varepsilon_{\beta}\right)_{\gamma}\right]
$$

Na qual $\left(\varepsilon_{\beta}\right)_{\gamma}$ é a probabilidade do detector beta detectar a radiação gama.

Em outros casos, em que há um segundo raio gama, existe a possibilidade de registro de coincidência e as equações se tornam: 


$$
\frac{N_{\beta} N_{\gamma}}{N_{c}} \cong N_{0}\left[1+\frac{\left(1-\varepsilon_{\beta}\right)}{\varepsilon_{\beta}}\left\{\left(\varepsilon_{\beta}\right)_{\gamma}-\varepsilon_{c} / \varepsilon_{\gamma}\right\}\right]
$$

$\mathrm{Na}$ qual $\varepsilon_{\mathrm{c}}$ é a probabilidade de um registro de coincidência entre duas radiações gama, quando uma partícula beta não é detectada.

Como já se mencionou anteriormente, a espessura da barreira no detector de radiação gama é suficiente para barrar as partículas beta, que são pouco penetrantes. Portanto, não são necessárias correções para este caso.

\subsubsection{Esquema de desintegração complexo}

A figura (2.5) mostra um esquema de desintegração um pouco mais complexo do que o apresentado na figura (2.4). Neste caso, após a emissão da partícula $\beta$ o átomo pode se encontrar no estado fundamental (não apresentando coincidência) ou alcançar um dos três estados excitados. No caso do esquema apresentado na figura (2.5) percebe-se que existem quatro ramos beta. 


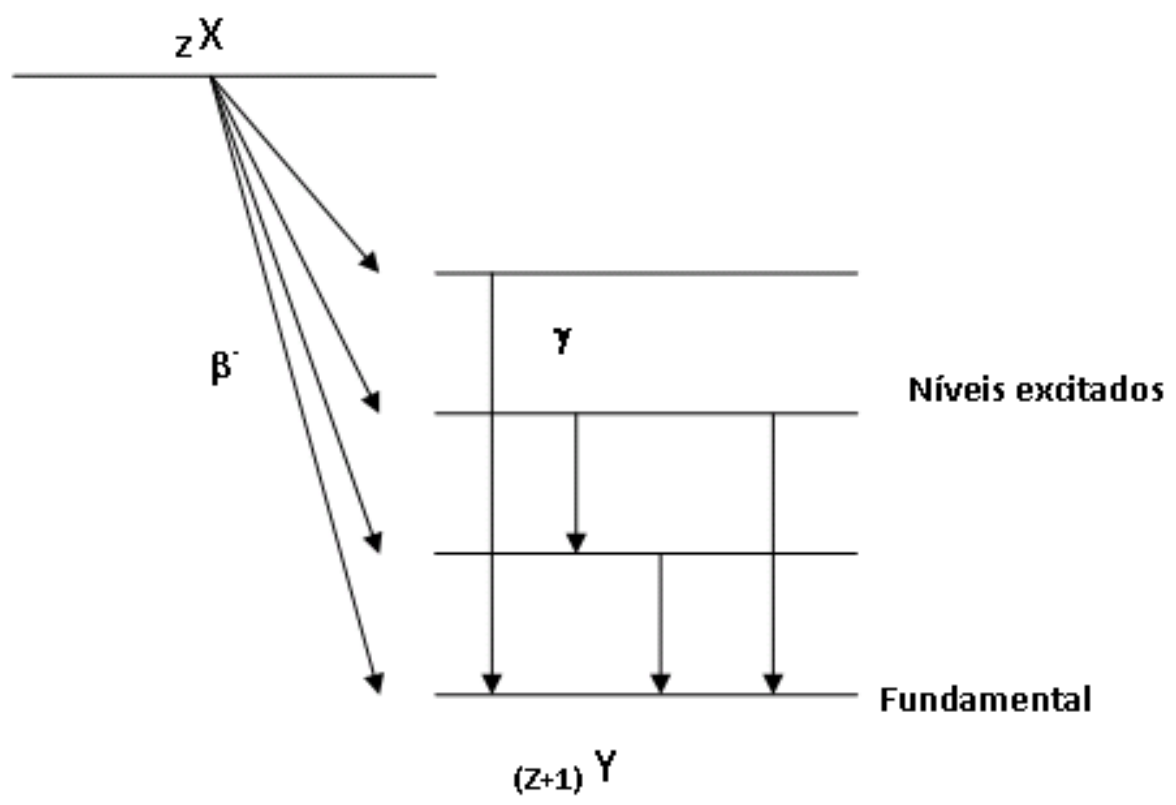

FIGURA 2.5: Esquema de desintegração com quatro ramos beta.

Para cada ramo beta é possível verificar coincidência com uma das transições gama, embora algumas apresentem maior probabilidade de ocorrer. É conveniente selecionar aquelas que apresentam maior probabilidade de ocorrer, pois são muito mais fáceis de detectar e implicam em erros menores. Para cada transição de interesse é selecionada uma "janela" gama que consiste em uma faixa de energia que abrange a energia de transição de interesse. Este procedimento evita que sejam registradas coincidências com fótons provenientes de outras transições.

As equações abaixo correspondem a uma representação mais completa, para o caso de um radionuclídeo que se desintegra por transições $\beta-\gamma$ com $m$ ramos beta: ${ }^{[10,16,20]}$. 


$$
N_{\beta}=N_{0} \sum_{i=1}^{m} a_{i}\left\{\varepsilon_{\beta_{i}}+\left(1-\varepsilon_{\beta_{i}}\right) \sum_{j=1}^{n} b_{i j} \frac{\alpha_{i j}\left[\varepsilon_{c e_{i j}}+\left(1-\varepsilon_{c e_{i j}}\right) \varepsilon_{(X, A)_{i j}}\right]+\varepsilon_{\beta \gamma_{i j}}}{\left(1+\alpha_{i j}\right)}\right\}
$$

$$
N_{\gamma}=N_{0}\left[\sum_{i=1}^{m} a_{i} \sum_{j=1}^{n} b_{i j} \varepsilon_{\gamma i j} \frac{1}{1+\alpha_{i j}}\right]
$$

$$
N_{c}=N_{0}\left\{\sum_{i=1}^{m} a_{i}\left[\varepsilon_{\beta_{i}} \sum_{j=1}^{n} b_{i j} \varepsilon_{\gamma_{i j}} \frac{1}{\left(1+\alpha_{i j}\right)}+\left(1-\varepsilon_{\beta_{i}}\right) \sum_{j=1}^{n} b_{i j} \varepsilon_{c_{i j}} \frac{1}{\left(1+\alpha_{i j}\right)}\right]\right\}
$$

Onde,

$N_{\beta}, N_{\gamma}$ e $N_{c}$ correspondem às contagens beta, gama e de coincidências, respectivamente;

$N_{0}$ é a atividade;

$m$ é o número de ramos beta;

$n$ é o número de transições associadas a cada ramo beta;

$a_{i}$ é a intensidade (probabilidade) de desintegração do i-ésimo ramo beta;

$b_{i j}$ é a intensidade (probabilidade) de desexcitação da j-ésima transição gama, associada ao i-ésimo ramo; 
$\varepsilon_{\beta i}$ é a eficiência do detector beta, associada ao i-ésimo ramo beta;

$\varepsilon_{\gamma j}$ é a eficiência do detector gama associada à j-ésima transição gama do i-ésimo ramo beta;

$\varepsilon_{e c i j}$ é a eficiência de detecção de elétrons de conversão, no detector beta, associados ao ao i-ésimo ramo beta e a j-ésima transição gama;

$\varepsilon_{(x, A) j i j}$ é a eficiência de detecção de raios $\mathrm{X}$ ou elétrons Auger, no detector beta, associados ao i-ésimo ramo beta e a j-ésima transição gama;

$\varepsilon_{\beta \gamma \text { ij }}$ é a eficiência de deteç̧ão de radiação gama no detector beta, associada ao i-ésimo ramo beta e a j-ésima transição gama;

$\alpha_{i j}$ é o coeficiente de conversão interna associado ao i-ésimo ramo beta e a j-ésima transição gama;

$\varepsilon_{c i j}$ é a eficiência de detecção de coincidência gama-gama associada ao iésimo ramo beta e a j-ésima transição gama.

Dividindo-se $N_{\beta} N_{\gamma}$ por $N_{c}$, tem-se:

$\frac{N_{\beta} N_{\gamma}}{N_{c}}=N_{0} \frac{\left\{\sum_{i=1}^{m} a_{i}\left\{\varepsilon_{\beta_{i}}+\left(1-\varepsilon_{\beta_{i}}\right) \sum_{j=1}^{n} b_{i j} \frac{\left.\alpha_{i j}\left[\varepsilon_{c e_{i j}}+\left(1-\varepsilon_{c e_{i j}}\right) \varepsilon_{(X, A)_{y}}\right]+\varepsilon_{\beta \gamma_{i j}}\right)}{\left(1+\alpha_{i j}\right)}\right\}\left[\sum_{i=1}^{m} a_{i} \sum_{j=1}^{n} b_{i j} \varepsilon_{\gamma i j} \frac{1}{1+\alpha_{i j}}\right]\right\}}{\left\{\sum_{i=1}^{m} a_{i}\left[\varepsilon_{\beta_{i}} \sum_{j=1}^{n} b_{i j} \varepsilon_{\gamma_{y}} \frac{1}{\left(1+\alpha_{i j}\right)}+\left(1-\varepsilon_{\beta_{i}}\right) \sum_{j=1}^{n} b_{i j} \varepsilon_{c_{y}} \frac{1}{\left(1+\alpha_{i j}\right)}\right]\right\}}$

$N_{c} / N_{\gamma}$, que corresponde à eficiência beta, fica da seguinte forma: 


$$
\frac{N_{c}}{N_{\gamma}}=\frac{\sum_{i=1}^{m} a_{i}\left[\varepsilon_{\beta_{i}} \sum_{j=1}^{n} b_{i j} \varepsilon_{\gamma_{i j}} \frac{1}{\left(1+\alpha_{i j}\right)}+\left(1-\varepsilon_{\beta_{i}}\right) \sum_{j=1}^{n} b_{i j} \varepsilon_{c_{i j}} \frac{1}{\left(1+\alpha_{i j}\right)}\right]}{\left[\sum_{i=1}^{m} a_{i} \sum_{j=1}^{n} b_{i j} \varepsilon_{\gamma^{i j}} \frac{1}{1+\alpha_{i j}}\right]}
$$

De acordo com as equações apresentadas acima, seria preciso conhecer detalhadamente o esquema de desintegração do radionuclídeo, assim como as eficiências dos detectores, com o máximo de precisão possível. Entretanto, para que seja possível manter a principal característica do método de coincidência, que é não depender do conhecimento do esquema de desintegração e das eficiências dos detectores, pode-se utilizar uma técnica conhecida como Técnica da Extrapolação da Eficiência. ${ }^{[9]}$

\subsubsection{Técnica da Extrapolação da Eficiência ${ }^{[9]}$}

A Técnica de Extrapolação da Eficiência tem como objetivo relacionar o parâmetro de eficiência beta $\left(\varepsilon_{\beta}\right)$, que pode ser escrito como $\left(N_{c} / N_{\gamma}\right)$, com as contagens no detector beta $\left(N_{\beta}\right)$ de forma que $N_{\beta} \rightarrow N_{0}$ quando $\left(N_{c} / N_{\gamma}\right) \rightarrow 1$, podendo-se, portanto, escrever a seguinte relação: $:^{[7,9,16,20]}$

$$
N_{\beta}=N_{0} F\left(\frac{N_{c}}{N_{\gamma}}\right)
$$

Onde $F$ é a função que relaciona $N_{\beta}$ com o parâmetro $N_{c} / N_{\gamma}$ e deve tender a 1 quando $N_{c} / N_{\gamma}$ tender a zero. 
Vale ressaltar que, no caso de radionuclídeos que apresentam vários ramos $\beta$, para que a equação (2.28) seja válida é necessário que as eficiências dos diversos ramos $\beta$ sejam escritas como função de uma única eficiência.

A equação (2.28) pode ser reescrita de outra forma:

$$
\frac{N_{\beta} N_{\gamma}}{N_{C}}=N_{0} G\left(\frac{1-\frac{N_{C}}{N_{\gamma}}}{\frac{N_{C}}{N_{\gamma}}}\right)
$$

A razão $\frac{N_{\beta} N_{\gamma}}{N_{c}}$ tende a $N_{0}$ quando $G$ tende a 1 , o que ocorre quando $\left(\frac{1-\frac{N_{c}}{N_{\gamma}}}{\frac{N_{c}}{N_{\gamma}}}\right)$ tende a zero.

A função $G$ varia mais lentamente que a função $F$, o que a torna mais conveniente para uma solução gráfica ou analítica, e pode ser obtida através de um ajuste polinomial dos pontos obtidos em um gráfico de $\frac{N_{\beta} N_{Y}}{N_{C}}$ por $\left(\frac{1-\frac{N_{C}}{N_{Y}}}{\frac{N_{C}}{N_{\gamma}}}\right)$ no qual se faz variar o parâmetro $1-\frac{N_{c}}{N_{\gamma}}$ (ineficiência do detector de radiação $\beta$ ) por meio de absorvedores. Uma vez encontrada a função $G$ pode-se extrapolá-la para o caso ideal em que a ineficiência $\left(1-\varepsilon_{\beta}\right)$ é igual a zero, ou seja, $1-\frac{N_{c}}{N_{\gamma}}$ seja zero. Outra maneira de se obter um ajuste é por meio da interpolação dos pontos experimentais com os pontos obtidos pela simulação, o que garante um acordo melhor com a realidade, uma vez que a função $G$ não é necessariamente um polinômio.

Todos os outros parâmetros da equação (2.29): $N_{\beta}, N_{\gamma}$ e $N_{c}$, são obtidos experimentalmente, podendo-se ignorar as eficiências do detectores e os parâmetros do esquema de decaimento do radioisótopo. 
Para uma melhor compreensão da técnica de extrapolação da eficiência pode-se analisar a equação (2.30) que representa uma versão simplificada da equação (2.26), pois considera apenas uma janela gama. Aplica-se para o caso de um radionuclídeo que se desintegra por emissão de partícula $\beta^{-}$e se desexcita por emissão de radiação gama. Em (2.30) são levadas em conta apenas as correções para a detecção de elétrons de conversão e fótons, no detector de radiação beta, obtendo-se, para cada "janela" gama:

$$
\frac{N_{\beta} N_{\gamma}}{N_{c}}=N_{0}\left[1+\frac{\left(1-\varepsilon_{\beta}\right)}{\varepsilon_{\beta}}\left(\frac{\alpha}{1+\alpha} \varepsilon_{C I}+\left(\varepsilon_{\beta}\right)_{\gamma}\right)\right]
$$

Na qual:

$\varepsilon_{\beta}$ é a eficiência beta total do contador proporcional;

$\alpha$ é o coeficiente de conversão total;

$\varepsilon_{I C}$ é a eficiência de detecção para os elétrons de conversão;

$\varepsilon_{\beta \gamma}$ é a eficiência de detecção para fótons no contador proporcional.

De acordo com a equação (2.30) percebe-se que quando $\left(1-\varepsilon_{\beta}\right)$, que é a ineficiência do detector beta, tende a zero, $\mathrm{N}_{\beta} \mathrm{N}_{\gamma} / \mathrm{N}_{c}$ tende a $N_{0}$, que é a atividade da fonte como na equação (2.29). Assim, pode-se variar a eficiência beta por meio de absorvedores de modo a obter uma curva, a qual poderá ser extrapolada para o valor ideal de $\left(1-\varepsilon_{\beta}\right)=0$, obtendo-se assim a atividade, sem ser necessário o conhecimento 
dos parâmetros do esquema de desintegração nem o conhecimento das eficiências beta e gama.

\subsection{Correções aplicadas às medidas no sistema $4 \pi \beta-\gamma^{[15,17]}$}

Para a obtenção do valor de atividade pelo método de coincidências é necessário que sejam feitas algumas correções com relação aos erros inerentes ao sistema de medidas.

\subsubsection{Tempo morto}

O sistema de detecção leva um tempo $(\tau)$ para processar um evento. Enquanto está processando este evento, o sistema não está disponível para detectar um novo evento que ocorra em um intervalo de tempo menor que $(\tau)$. Este intervalo de tempo no qual o sistema de detecção fica inoperante é chamado de tempo morto do sistema de deteç̧ão.

A correção é calculada da seguinte maneira: ${ }^{[16]}$

$$
N=\frac{N^{\prime}}{1-N^{\prime} \cdot \tau}
$$

Onde $\mathrm{N}^{\prime}$ é a taxa de contagens do detector e $\tau$ é o tempo morto do sistema.

\subsubsection{Radiação de fundo}

Radiações que não são provenientes da fonte também podem ser detectadas. Esta radiação de fundo (background) pode ser obtida fazendo-se uma 
medida com a fonte e outra sem a fonte, com a mesma duração. Para obter as contagens apenas da fonte basta subtrair a radiação de fundo.

\subsubsection{Decaimento radioativo}

Fontes com meia-vida pequena, comparada ao tempo de medida, necessitam que se faça uma correção para o decaimento ao longo do tempo de medida. Esta correção é dada por:

$$
N_{r e f}=N \frac{\lambda t}{1-e^{-\lambda t}} e^{\lambda\left(t_{m}-t_{r e f}\right)}
$$

Onde,

$N_{\text {ref }}$ é a atividade da fonte na data de referência;

$N$ é a atividade da fonte na data de medida;

$t_{\text {ref }}$ é a data de referência;

$t_{m}$ é a data da medida;

$t$ é o tempo de medida;

$\lambda$ é a constante de decaimento.

\subsubsection{Correção para coincidências acidentais}

Coincidências acidentais podem ocorrer quando duas radiações não coincidentes são emitidas em um tempo menor que o tempo de resolução do sistema de detecção. A correção é feita de acordo com o formalismo de Cox e Isham $^{[20]}$, o qual foi adaptado por Smith ${ }^{[21]}$. 


\subsection{Programa para análise de dados}

Para a realização deste trabalho foram utilizados alguns softwares, desenvolvidos no LMN, um deles especificamente para os cálculos do método de coincidências ${ }^{[19,20]}$, denominado CONTAC ${ }^{[22]}$. Este programa faz o cálculo da atividade da fonte radioativa. Ele recebe as seguintes informações como dados de entrada: tempo de meia-vida da fonte com sua respectiva incerteza em porcentagem, data e hora de referência (a partir da qual é calculada a correção para o decaimento radioativo); o número de contagens beta, gama e de coincidência, além de informações sobre o $B G$, a fim de calcular a atividade da fonte juntamente com sua incerteza. Neste programa estão incorporadas todas as correções necessárias ao cálculo da atividade, tais como: correção para o decaimento radioativo da fonte; correção para o tempo morto do sistema de detecção $4 \pi(\mathrm{PC})$-Nal(TI); correção para radiação de fundo e correção para coincidências acidentais.

\subsection{Determinação da probabilidade de emissão gama por decaimento}

Para a medida das probabilidades de emissão das transições gama é conveniente a utilização de um sistema de espectrometria gama contendo um detector HPGe (Germânio Hiperpuro), o qual possui uma excelente resolução em energia.

O HPGe é um detector do tipo semicondutor usualmente utilizado para detecção de radiações $X$ e gama. A radiação detectada é amplificada e enviada a um Conversor Analógico Digital (ADC) associado a um analisador multicanal. Um histograma é gerado a partir desta distribuição de contagens, correspondendo ao espectro de altura de pulsos, que representa a distribuição das energias absorvidas no interior do detector.

Por meio deste detector é possível distinguir picos de energia muito próximos, devido a sua alta resolução, permitindo uma análise muito acurada dos 
dados. Além disso, é possível obter-se uma relação entre energia e intensidade gama. Para isto torna-se necessária uma calibração com fontes radioativas que sejam padronizadas em atividade e que possuam características bem conhecidas, tais como: meia-vida e probabilidades de emissão gama por decaimento. A atividade pode ser determinada por meio do método de coincidência $4 \pi \beta-\gamma$, que é um método de padronização primário.

\subsubsection{Equação Básica}

A probabilidade de emissão gama por decaimento pode ser obtida pela seguinte equação:

$$
I_{\gamma}=\frac{S}{\varepsilon_{\gamma} N_{0}}
$$

Onde,

S é a área líquida do pico de absorção total da energia gama de interesse;

$I_{\gamma}$ é a probabilidade de emissão gama por decaimento da transição gama;

$N_{0}$ é a atividade da fonte padrão.

$\varepsilon_{\gamma}$ é a eficiência do detector gama.

A área líquida do pico de absorção total $(S)$ é obtida pela medida com o espectrômetro gama. $N_{0}$ pode ser obtida pelo método de coincidências $\beta-\gamma$ e $\varepsilon_{\gamma}$ é obtida por meio da calibração do detector com a utilização fontes padrões. 


\subsubsection{Curva de eficiência do espectrômetro gama}

A eficiência do detector gama, para cada valor de energia, pode ser obtida a partir da mesma equação (2.33) citada anteriormente, trocando $\varepsilon_{\gamma}$ de lugar com $I_{\gamma}$ :

$$
\varepsilon_{\gamma}(E)=\frac{S}{I_{\gamma}(E) N_{0}}
$$

Utilizando diferentes fontes padrões cujas transições gama apresentem diferentes valores de energia e cujos valores de probabilidade de emissão gama sejam bem conhecidos, é possível obter a eficiência em função da energia. Para isto é utilizado um gráfico de em função de $E$ (energia da transição), normalmente em uma escala log-log. Um ajuste polinomial permite encontrar a função que relaciona $\varepsilon_{\gamma} \operatorname{com} E$.

Quanto maior for a diversidade dos valores de energia de transição gama das fontes padrões, mais abrangente e mais acurada será a curva de eficiência obtida.

\subsubsection{Correções aplicadas}

É necessário que sejam feitas algumas correções para a obtenção das probabilidades de emissão gama, conforme se mostra a seguir:

\subsubsection{Correção para tempo morto, radiação de fundo e decaimento radioativo}

Estas correções normalmente são feitas da forma descrita nos itens 2.4.1, 2.4.2 e 2.4.4. O software MAESTRO ${ }^{[23]}$, utilizado para a aquisição dos dados, indica tanto o real time, tempo total da medida, quanto o live time, já corrigido para o tempo morto. Entretanto, para este trabalho, o tempo morto foi obtido pela técnica do 
pulsador, que consiste em utilizar um pulso com a freqüência da rede elétrica $(60 \mathrm{~Hz})$ em um dos canais. Através do tempo de medida e do valor da freqüência é possível saber o número de contagens que deveriam ser registradas, para o pulsador. No entanto, o número de contagens reais é sempre menor, devido ao tempo morto do sistema. Pela diferença entre o número de contagens registradas e o número de contagens calculadas é possível obter o tempo morto.

\subsubsection{Fator geométrico}

Todas as fontes de ${ }^{177} \mathrm{Lu}$ utilizadas nas medidas para este trabalho, bem como as fontes-padrão, foram preparadas com a mesma geometria, em filmes finos de Collodion. Por este motivo pode-se considerar igual a 1 a correção para fator geométrico e, também igual a 1, a correção para atenuação na própria fonte. ${ }^{[15,17]}$

\subsubsection{Efeito soma}

Quando um radionuclídeo emite radiação em cascata com intervalo de tempo menor do que o tempo de resolução do sistema de detecção pode ocorrer que dois fótons emitidos em cascata sejam registrados como um único fóton com energia igual à soma das energias dos dois fótons incidentes. Neste caso, os dois picos correspondentes às energias dos fótons incidentes ficarão com a contagem menor do que deveria, enquanto que o pico correspondente à soma das energias dos fótons ficará maior.

A probabilidade de ocorrência do efeito soma independe da atividade da fonte, mas está fortemente relacionada com a eficiência total do detector, ou seja, detectores com maior volume sensível, ou com menor distância fonte-detector, apresentam maior probabilidade de registrar a ocorrência de efeito soma. 
A correção para efeito soma foi efetuada por meio de um software, descrito no item a seguir.

\subsubsection{Programas de Análise de dados}

Foram utilizados quatro programas para os cálculos com o espectrômetro de HPGe: determinação das eficiências, determinação das intensidades e correções.

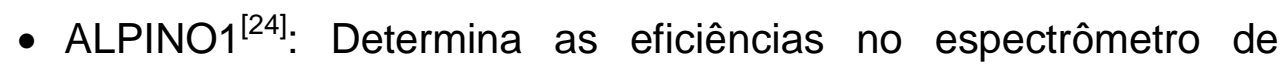
HPGe, a partir de medidas das fontes padronizadas em atividade. Com base nos parâmetros gerados pelo LOGFIT (descrito a seguir) calcula as eficiências gama do radionuclídeo de interesse em função da atividade previamente determinada.

- ALPINO4 ${ }^{[25]}$ : É uma versão mais sofisticada do ALPINO, que tem como principal característica a analise mais detalhada das áreas sob os picos de absorção total do espectro gama, incluindo um background na forma de degrau suavizado sob o pico de absorção total da linha gama de interesse.

- LOGFIT: Com base nas eficiências obtidas por meio das fontes padrões, usadas para calibração do detector (HPGe), gera um arquivo com os parâmetros da função de ajuste por mínimos quadrados, que relaciona a energia das transições gama com as respectivas eficiências.

- COINCIG ${ }^{[26]}$ : Com base no esquema de desintegração do radionuclídeo calcula os fatores de correção para efeito soma por meio de uma simulação de emissão de fótons em cascata. 


\subsection{Simulação por Monte Carlo}

Paralelamente às medidas feitas no sistema $4 \pi \beta-\gamma$, foi feita uma simulação utilizando o método de Monte Carlo, utilizando-se o programa ESQUEMA ${ }^{[27]}$. Por meio desta simulação foi possível reproduzir completamente o experimento e obter uma curva de extrapolação teórica.

A importância da simulação está no fato de que ela permite que se ajuste de maneira mais adequada o experimento, determinando, por exemplo, o intervalo de energia mais apropriado para as "janelas" gama. Além disto, os resultados da curva de extrapolação teórica permitem um ajuste por interpolação dos dados experimentais, com um resultado mais satisfatório do que o obtido com ajustes polinomiais.

\subsubsection{Cálculo das funções de resposta dos detectores do sistema $4 \pi \beta-\gamma$}

Para simular a resposta de cada detector foi utilizado o código Monte Carlo $\mathrm{MCNPX}^{[28]}$. Uma representação completa da situação experimental foi feita, incluindo detalhes do substrato da fonte, e dos absorvedores, para garantir a maior proximidade possível com o experimento. A figura (2.6) mostra que a reprodução da situação experimental é bastante detalhada. A região em verde, no centro da figura, representa o gás P-10 dentro do volume do contador proporcional (PC); em azul estão representados os dois cintiladores de $\mathrm{Nal}(\mathrm{TI})$; em laranja está representada a blindagem de chumbo. Em lilás está representado o ar. Em rosa está representada toda a estrutura do detector proporcional, construída em latão. Em destaque, a fonte (branco) está no centro da estrutura; em verde uma fina camada de Collodion e em azul a arandela de aço inox na qual o Collodion está fixado.

As dimensões de cada figura estão rigorosamente de acordo com a situação real experimental, pois isto garante que a simulação reproduza corretamente os resultados experimentais. 


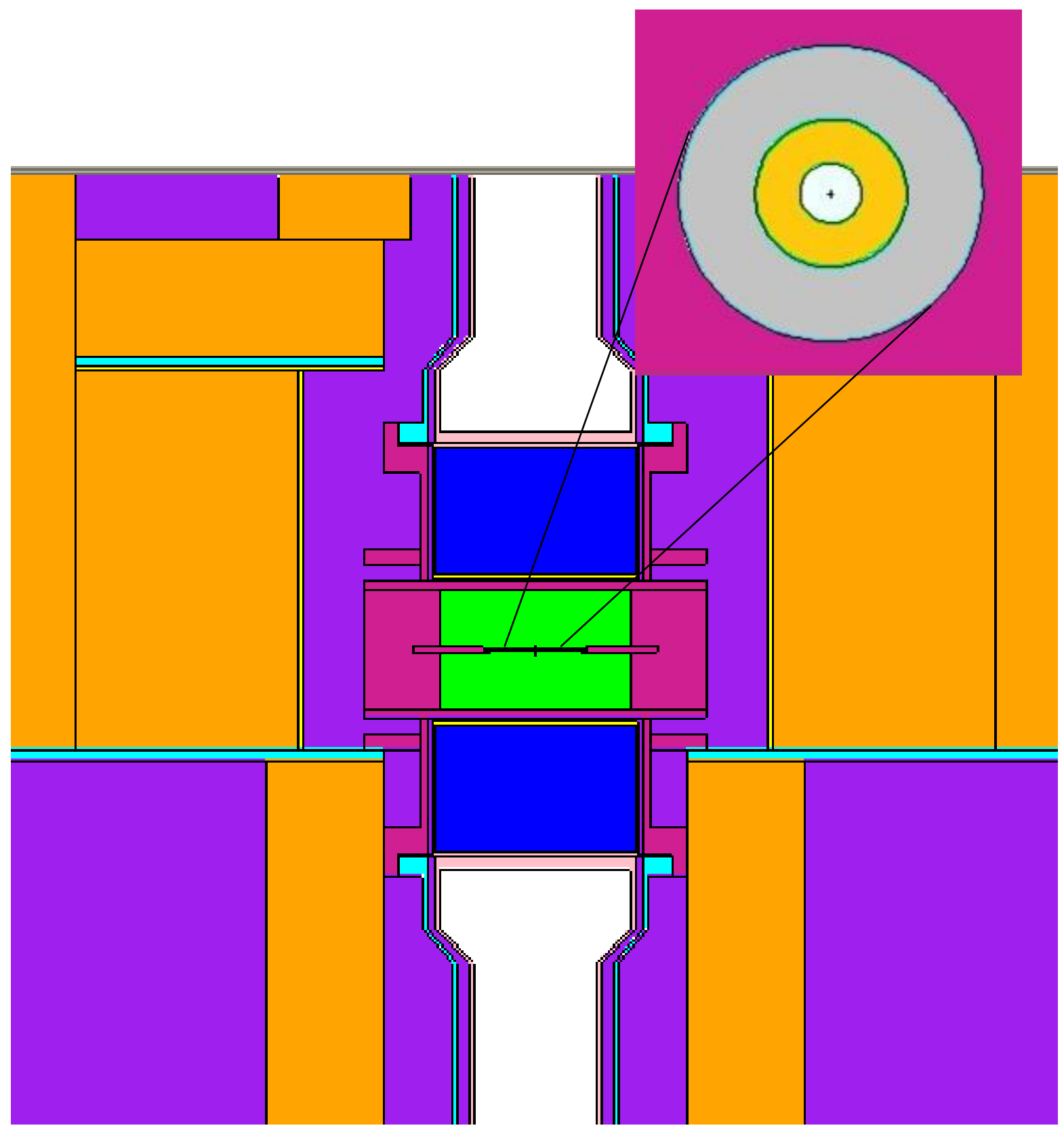

FIGURA 2.6: Representação detalhada da situação experimental utilizada para a simulação por Monte Carlo. A região em verde representa o gás P-10 dentro do volume do contador proporcional (PC); em azul estão representados os dois cintiladores de $\mathrm{Nal}(\mathrm{TI})$; em laranja está representada a blindagem de chumbo. Em lilás está representado o ar. Em rosa está representada toda a estrutura do detector proporcional, construída em latão. Também é possível observar na figura detalhes da fonte: Em branco a fonte, em dourado o Collodion metalizado com ouro e em cinza claro a arandela de aço inox. 
Simulação do esquema de desintegração

O comportamento do radioisótopo foi simulado por outro código Monte Carlo chamado ESQUEMA ${ }^{[27]}$, o qual foi desenvolvido no LMN. Com base em informações como meia-vida, coeficientes de conversão interna, probabilidade de emissão gama, entre outros dados, o ESQUEMA simula todas as transições que ocorrem a partir do ${ }^{177} \mathrm{Lu}$ (radionuclídeo precursor) até o ${ }^{177} \mathrm{Hf}$ (núcleo filho), incluindo todos os processos de detecção no sistema de coincidência, para os quais utiliza-se das tabelas de respostas de todos os componentes do sistema de detecção, geradas pelo MCNPX. Dessa forma, o experimento pôde ser simulado completamente, e a equação (2.25) pode ser reproduzida teoricamente. 


\section{PARTE EXPERIMENTAL}

\subsection{Sistema $4 \pi(\mathrm{PC}) \beta-\gamma$}

Para a realização das medidas é necessária a utilização de detectores adequados para cada uma das radiações coincidentes. Para detecção da radiação beta é utilizado um contador proporcional (PC) com geometria $4 \pi$ e que pode utilizar gás fluente ou pressurizado ${ }^{[6]}$. Para detecção da radiação gama são utilizados dois cintiladores de $\mathrm{Nal}(\mathrm{TI})$. No LMN existem duas configurações possíveis. Em uma delas, denominada sistema $I$, utiliza-se um único cintilador $\mathrm{Nal}$. $\mathrm{Na}$ outra configuração são utilizados dois cintiladores, um por cima e outro por baixo da fonte, conforme se observa no diagrama apresentado na figura (3.2) e na foto da imagem (3.1). Esta configuração, denominada sistema II, utilizada neste trabalho, permite uma eficiência maior na detecção dos fótons emitidos pela fonte.

O sinal captado pelos detectores é registrado separadamente. Os sinais gama e beta que chegam simultaneamente são registrados no registrador de coincidência. Os dados obtidos pelos detectores são armazenados sob a forma de arquivo (.CHN) por meio da utilização do software MAESTRO, e posteriormente processados pelo CONTAC, descrito no capítulo (2.5).

A figura (3.1) é uma fotografia do aparato experimental do sistema // de coincidências. Em (3.1.a) é possível visualizar a blindagem, composta por blocos de chumbo, que tem a finalidade de diminuir a radiação de fundo impedindo a entrada de radiações provenientes de fontes externas. No centro da figura, no interior do castelo de chumbo, encontra-se o contador proporcional dentro do qual é inserida a fonte. Também podem ser observados os cintiladores de $\mathrm{Nal}(\mathrm{TI})$, em formato cilíndrico, por cima e por baixo do contador proporcional. 


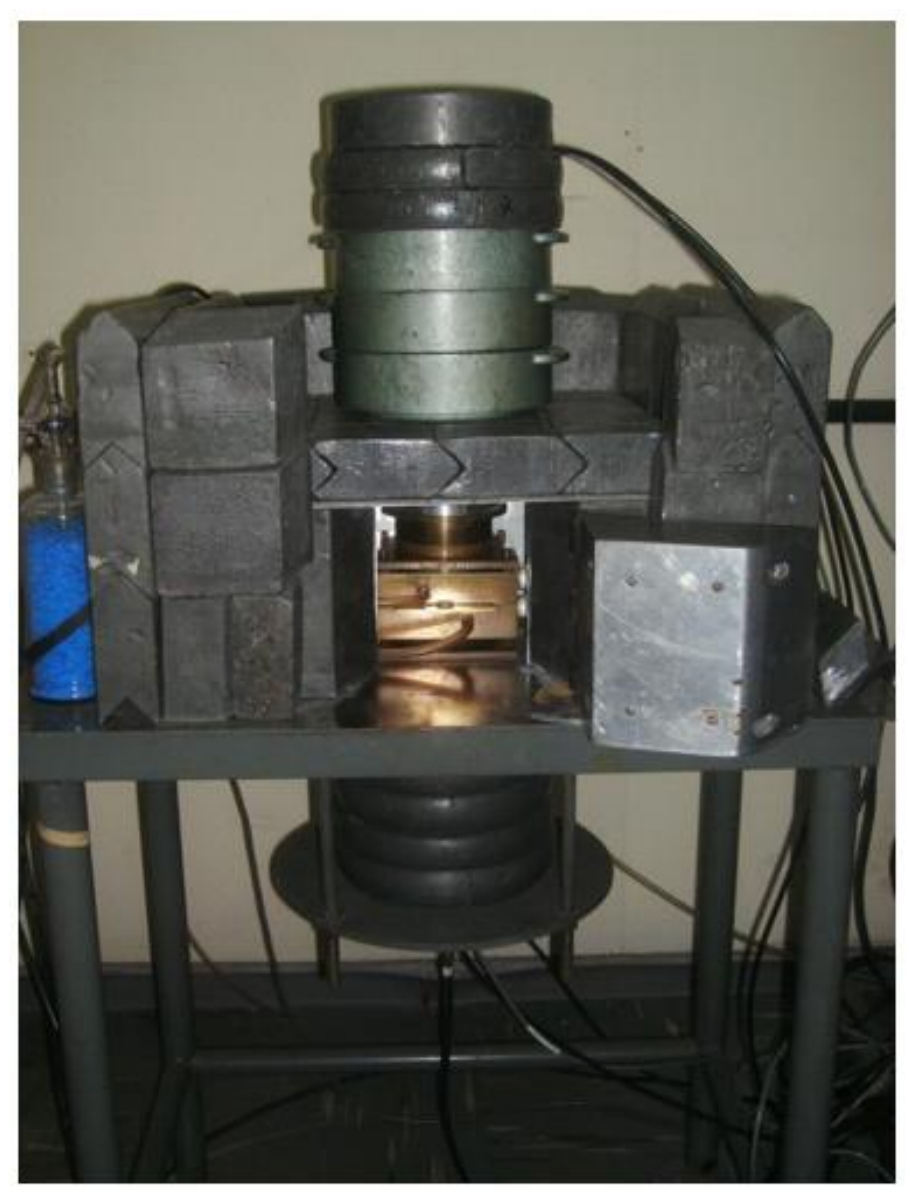

(a)

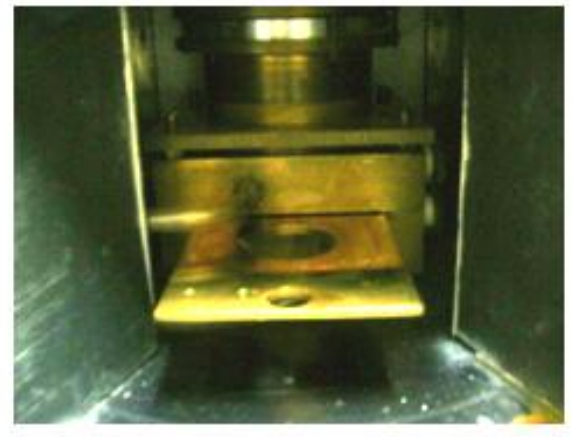

(b)

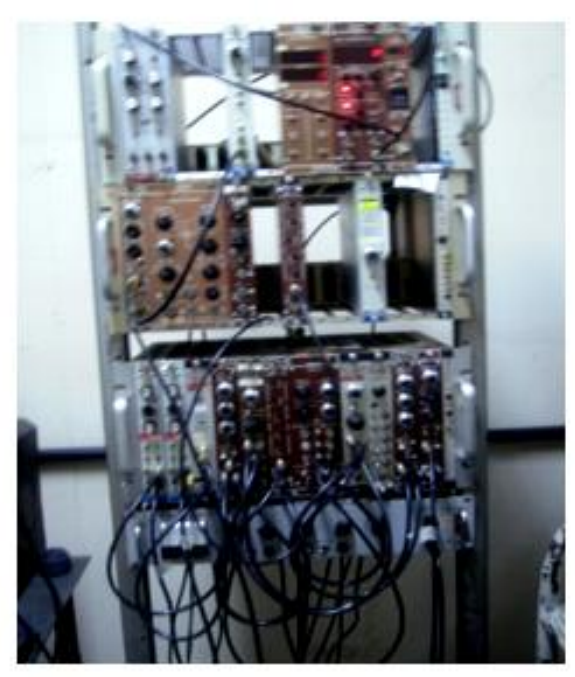

(c)

FIGURA 3.1: Arranjo experimental do sistema II. (a) Os blocos de chumbo formam a blindagem que impede a detecção de radiações de fontes externas. Em cima e em baixo os cintiladores $\mathrm{Nal}(\mathrm{TI})$. No centro da figura, no interior do "castelo" de chumbo a estrutura do contador proporcional no qual a fonte é inserida. (b) Gaveta na qual é inserida a fonte. Após ser fechada, ela fica no centro do contador proporcional. (c) Alguns dos módulos eletrônicos utilizados. Os mesmos aparecem no diagrama da figura (3.2).

$\mathrm{Na}$ figura (3.1.b) uma ampliação da gaveta na qual a fonte é inserida. Quando fechada fica no centro do contador proporcional. Em (3.1.c) alguns dos 
módulos utilizados que aparecem de forma mais detalhada no diagrama mostrado na figura (3.2).

\subsubsection{Contador Proporcional (PC)}

Para a detecção de radiação alfa, beta, elétrons ou raios $X$, é utilizado um contador proporcional em geometria $4 \pi$. No LMN é possível utilizar um contador proporcional com gás fluente ou pressurizado. Para o caso do ${ }^{177} \mathrm{Lu}$ foi utilizado o sistema com gás fluente. O gás, conhecido como P-10, é mantido a uma pressão de 0,1 MPa e é composto de $10 \%$ de metano e $90 \%$ de argônio. Antes de chegar ao detector, o gás passa por um dispositivo que contém sílica para retirar a sua umidade.

A geometria $4 \pi$ é ideal para os casos em que a fonte é uma pequena amostra do radioisótopo e pode ser colocada no interior do volume do detector. A grande vantagem de ter a fonte no interior do detector é o fato de não ser necessária uma "janela" de entrada entre a fonte e o volume ativo do detector, como ocorre na geometria cilíndrica, por exemplo. Neste caso a "janela" pode causar uma significativa atenuação em radiações pouco penetrantes.

A geometria $4 \pi$ leva vantagem sobre a $2 \pi$ nos casos em que a fonte é preparada em um substrato muito fino, em relação ao alcance da radiação ${ }^{[3]}$. Sendo assim a fonte pode emitir radiação por cada uma de suas superfícies, tornando muito mais adequado o uso da geometria $4 \pi$.

\subsubsection{Cintilador de $\mathrm{Nal}(\mathrm{TI})$}

Os cintiladores de $\mathrm{Nal}(\mathrm{TI})$, utilizados no presente trabalho, possuem uma dimensão de $76 \mathrm{~mm}$ de altura por $76 \mathrm{~mm}$ de diâmetro e apresentam uma alta eficiência para a detecção de fótons gama. Em razão desta alta sensibilidade do 
detector torna-se necessária a utilização de uma blindagem com chumbo, para reduzir a influência de fótons provenientes do meio externo.

A configuração do sistema // torna necessário a utilização de um módulo soma, que une as informações provenientes de cada cintilador, como pode-se observar na figura (3.2).

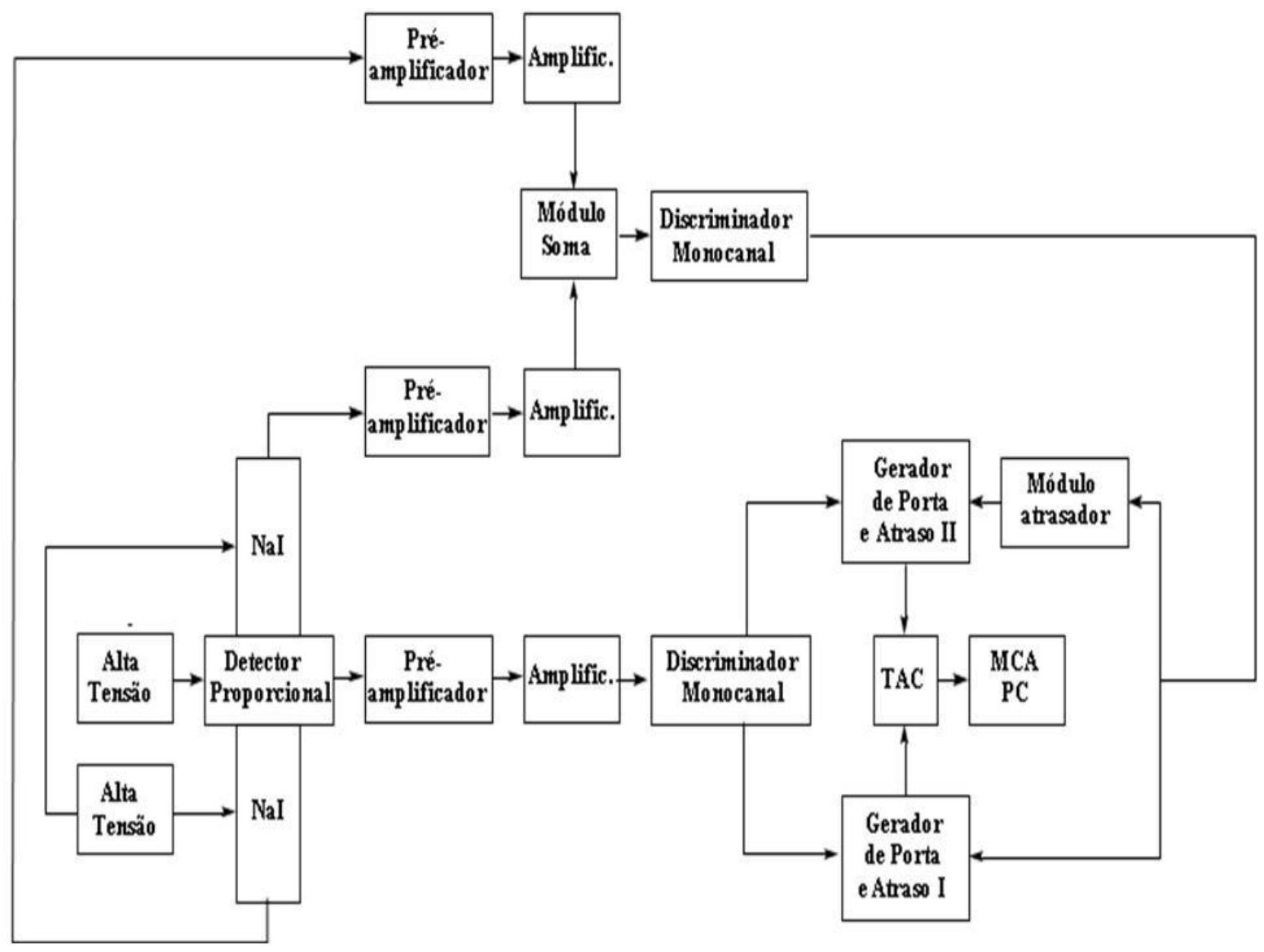

FIGURA 3.2: Diagrama do Sistema de Coincidências $4 \pi \beta-\gamma^{[19]}$. 


\subsubsection{Arranjo do sistema eletrônico ${ }^{[15,17]}$}

A figura (3.2) mostra um esquema do sistema eletrônico associado aos detectores.

Pode-se dividir o sistema eletrônico em duas vias:

- $\quad$ Via $\beta$ (associada ao contador proporcional): Pela figura (3.2) é possível acompanhar, pela via $\beta$, o percurso de um pulso elétrico gerado pelo contador proporcional, no momento em que este detecta uma radiação $\beta$. Após sair do detector o pulso é pré-amplificado e amplificado. Em seguida passa por um discriminador, o que permite que sejam eliminados os ruídos eletrônicos. Depois disto o pulso é dividido em dois, de forma que uma parte passa pelo gerador de porta e atraso I (delay) e a outra parte pelo gerador de porta e atraso II. Os pulsos provenientes dos geradores de porta e atraso seguem, então, para o sistema TAC, o qual será descrito mais adiante.

- $\quad$ Via $\gamma$ (associada ao cintilador $\mathrm{Nal}(\mathrm{TI})$ ): Assim como na via $\beta$, os pulsos gerados pelos cintiladores passam por pré-amplificadores e amplificadores, mas como são utilizados dois cintiladores distintos é necessário que o pulso passe por um módulo soma, com a função de somar os sinais de cada detector. Após passar pelo módulo soma o pulso passa por um discriminador monocanal, que neste caso tem a função de selecionar a região do espectro (que pode abranger um ou mais picos de absorção total). É desta forma que são selecionadas as "janelas" gama, ou seja, as energias de interesse. O pulso é então dividido em duas partes de forma que uma delas vai direto para o gerador de porta e atraso I, enquanto o outro vai para um módulo atrasador antes de ir para o gerador de porta e atraso II. Os pulsos seguem para o sistema TAC. 
O módulo TAC (Time to Amplitude Converter) converte diferença de tempo em amplitude (altura de pulso). De acordo com a figura (3.2) o módulo TAC recebe pulsos das duas vias. Um pulso determina o início (start) e o outro determina 0 término (stop). Quando o start e o stop são determinados por pulsos provenientes unicamente da via $\beta$ é registrada uma contagem $\beta$. Da mesma forma, quando ambos os pulsos forem provenientes da via $\gamma$, uma contagem $\gamma$ é registrada. Uma contagem de coincidência é registrada quando um pulso proveniente da via $\beta$ dá o start e o pulso proveniente da via $\gamma$ o stop, ou vice-versa.

\subsubsection{Preparo da Fonte Radioativa}

A solução radioativa de ${ }^{177} \mathrm{Lu}$ para padronização primária foi fornecida durante uma comparação internacional patrocinada pelo Bureau International des Poids et Mesures (BIPM), França. As fontes radioativas foram preparadas depositando-se alíquotas no centro de um substrato de Collodion de $20 \mu \mathrm{g} \mathrm{cm}^{-2}$, previamente revestido com uma camada de ouro de $10 \mathrm{mg} \mathrm{cm}^{-2} .0$ processo de secagem foi feito com jato de nitrogênio a $45^{\circ} \mathrm{C}$, para evitar a formação de cristais, que podem ocorrer no processo de secagem.

A massa da fonte radioativa foi determinada pelo Método do Picnômetro ${ }^{[29]}$, que consiste em medir a massa de um picnômetro, com a solução radioativa, e medila novamente depois que a fonte é depositada no substrato. Isto é feito por meio de uma balança analítica, cuja incerteza é da ordem de $15 \mu \mathrm{g}$. A diferença de massa corresponde à massa da fonte.

Para este trabalho foram preparadas 10 fontes com massas diferentes. Cada uma delas foi medida no sistema $4 \pi \beta-\gamma$, com tempo de medida de 400 segundos. A fonte que apresentou maior eficiência foi escolhida para uma série de 10 medidas em que a eficiência foi variada. 


\subsubsection{Variação da eficiência beta}

A variação na eficiência foi obtida por meio do revestimento da fonte, por cima e por baixo, com finas camadas de Collodion. A cada nova camada de Collodion a fonte foi medida novamente, acrescentando mais um ponto ao gráfico de ineficiência. A partir do gráfico gerado por estes pontos foi possível extrapolar a curva e encontrar o valor da atividade.

\subsection{Espectrômetro Gama com Detector HPGe ${ }^{[15,17]}$}

Uma calibração prévia do detector HPGe utilizando fontes padrões, tais como ${ }^{152} \mathrm{Eu},{ }^{214} \mathrm{Am},{ }^{133} \mathrm{Ba},{ }^{60} \mathrm{Co}$ e ${ }^{166 \mathrm{~m}} \mathrm{Ho}$, possibilitou a obtenção da eficiência como função da energia, permitindo, assim, a determinação da probabilidade de emissão gama por decaimento para as transições de 208 e $113 \mathrm{keV}$.

A partir do conhecimento dos valores de atividade e probabilidade de emissão gama por decaimento das fontes radioativas padrões, foi possível obter-se os valores de eficiência para cada uma das energias gama analisadas. Este cálculo foi feito pelo programa ALPINO. A eficiência foi determinada pela seguinte relação:

$$
\varepsilon_{\gamma}=\frac{S}{I_{\gamma} N_{0}}
$$

Onde:

S é a área líquida do pico de absorção total da energia gama de interesse;

$I_{\gamma}$ é a probabilidade de emissão gama por decaimento da transição gama; 
$N_{0}$ é a atividade da fonte padrão.

Com base nestes valores de eficiência foi efetuado um ajuste polinomial de grau 5, em escala log-log da curva de eficiência, abrangendo a faixa de energia gama entre 59,54 e $1408 \mathrm{keV}$, aplicando-se o método de mínimos quadrados.

A partir do ajuste da curva de eficiência do detector HPGe e da padronização da solução de ${ }^{177} \mathrm{Lu}$ no sistema de coincidências $4 \pi \beta-\gamma$, foram determinadas as probabilidade de emissão gama por decaimento para este radionuclídeo.

Esta intensidade é dada pela seguinte relação:

$$
I_{\gamma L u}=\frac{S}{\varepsilon_{\gamma} N_{O L u}}
$$

Onde o índice $L u$, corresponde ao ${ }^{177} \mathrm{Lu}$.

O detector de HPGe utilizado Laboratório de Metrologia Nuclear (LMN) do IPEN possui marca Canberra, modelo GX020, com um diâmetro de $57,7 \mathrm{~mm}$ e altura de 41,5 mm. Assim como para os detectores Nal(TI), para o HPGe é necessária uma blindagem de chumbo, como pode ser observado na figura (3.3), para minimizar a detecção de radiações externas, uma vez que este detector é bastante sensível. As medidas feitas no detector HPGe geram arquivos $\mathrm{CHN}$, os quais são processados pelo programa ALPINO. A figura (3.3) é uma fotografia do sistema de detecção do HPGe. No centro da figura o suporte de lucite sobre o qual é colocada a fonte, e que está localizado sobre o detector HPGe. Ao redor, está posicionada uma blindagem de chumbo com $10 \mathrm{~cm}$ de espessura. Em baixo da estrutura de chumbo pode ser vista parte de um criostato de nitrogênio líquido. A baixa temperatura é indispensável para o funcionamento do HPGe e, além disto, proporciona uma diminuição no ruído eletrônico e garante uma alta resolução. 


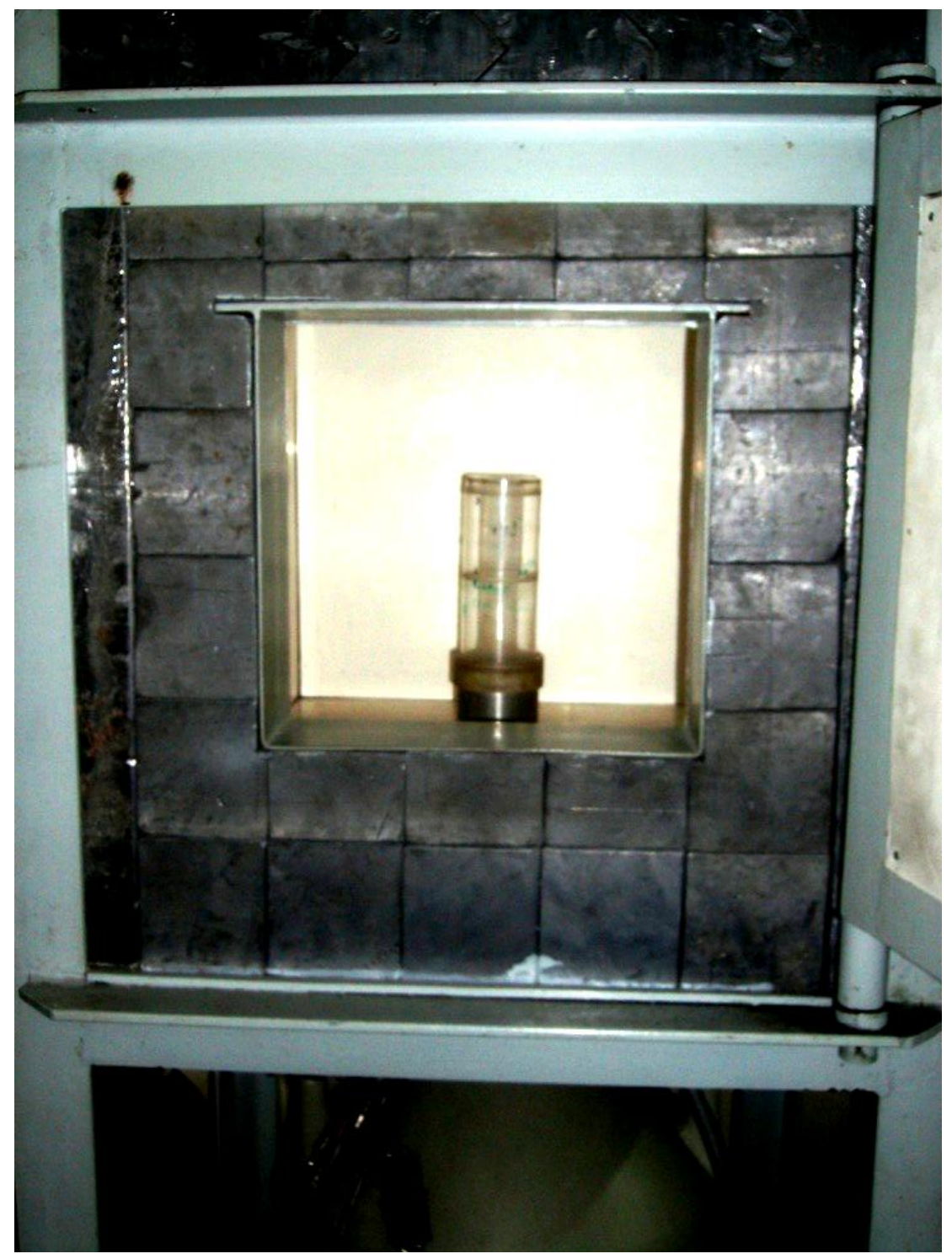

FIGURA 3.3: fotografia do sistema de medidas do HPGe. No centro o suporte de lucite localizado sobre o detector HPGe sob o qual é colocado a fonte. Ao redor uma reforçada blindagem de chumbo.

A figura 3.4 mostra um diagrama do sistema eletrônico associado ao HPGe. Após sair do detector o pulso é pré-amplificado e amplificado e segue para o analisador multicanal. 


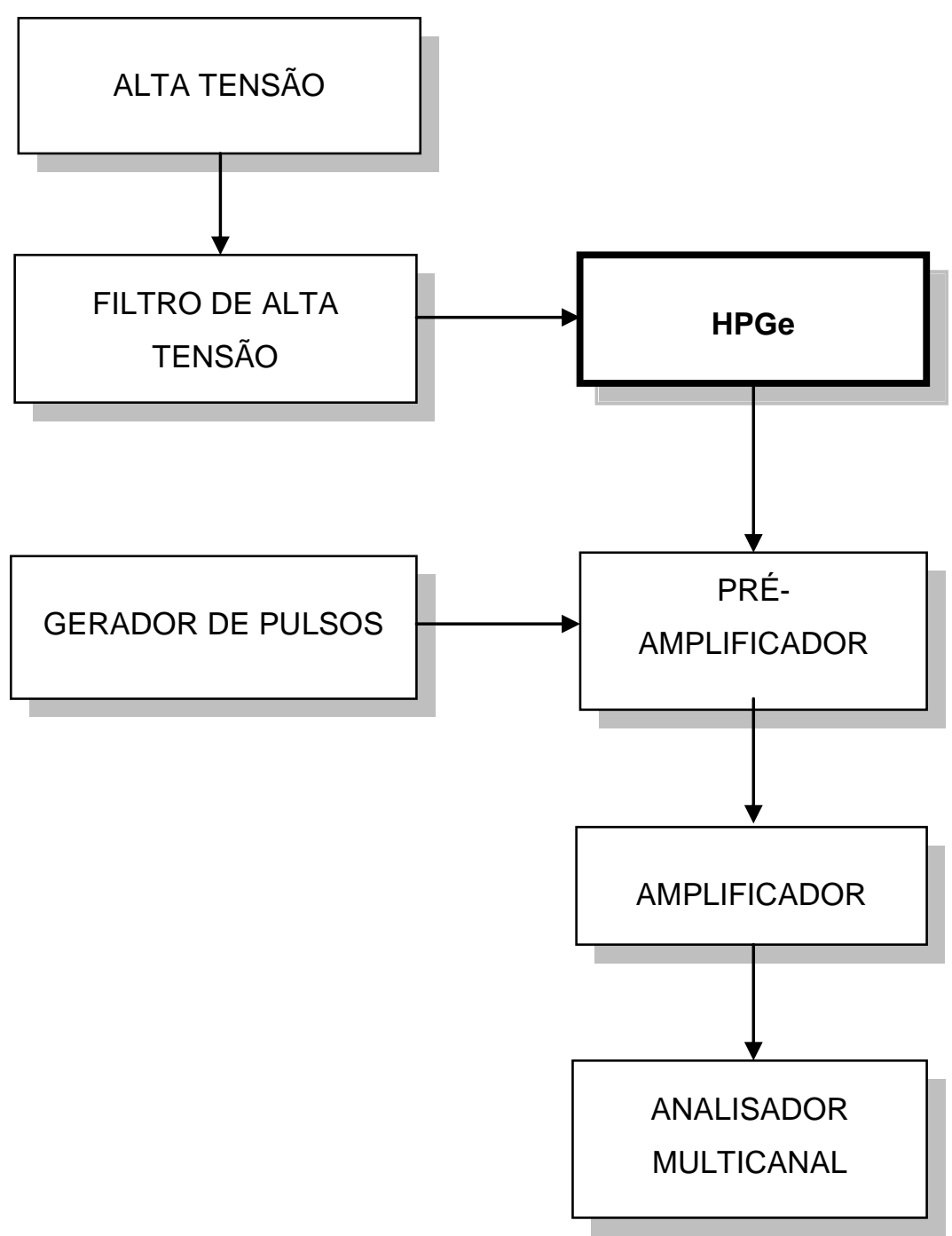

FIGURA 3.4: Diagrama do sistema eletrônico associado ao HPGe.

\subsubsection{Medida da probabilidade de emissão gama das transições de 113 e 208 $\mathrm{keV}$}

A medida no detector HPGe para a obtenção das probabilidade de emissão gama demanda um tempo muito maior do que no sistema $4 \pi \beta-\gamma$. O tempo de medida estabelecido foi de 50000 segundos, para cada uma das fontes, e uma medida com a mesma duração para a obtenção do background. O longo tempo de medida possibilitou reduzir à incerteza associada ao valor final. Foram medidas no 
HPGe as mesmas 10 fontes que se utilizou para a determinação da atividade no sistema de medidas $4 \pi \beta-\gamma$.

Utilizando-se o programa ALPINO foi possível utilizar o arquivo resultante da medida no HPGe, juntamente com seu background para encontrar o valor da probabilidade de emissão gama em função da energia.

\subsubsection{Medida da probabilidade de emissão gama das transições de 136 e 249 keV.}

Para determinar a probabilidade de emissão gama por decaimento das transições de menor intensidade foi feita uma análise relativa, levando em conta os resultados obtidos para a transição de 208 e $113 \mathrm{keV}$. Para isto foram preparadas 7 novas fontes cujos valores de atividade eram maiores do que os das fontes medidas inicialmente, com o objetivo de melhorar a estatística e obter resultados com incertezas menores. Foi utilizado o programa ALPINO com os seguintes dados de entrada:

- Energia de cada transição juntamente com seu valor de incerteza.

- Eficiência do detector para cada valor de energia de transição.

- Intensidade gama: o valor de probabilidade de emissão gama obtido para a transição de $208 \mathrm{keV}$ foi inserido como dado de entrada para cada um dos valores de energia.

Desta forma, a partir dos valores de atividade calculados pelo ALPINO e da relação entre o valor de atividade e o de intensidade fornecidos para a transição de referência (208 keV), pode-se calcular o valor da probabilidade de emissão para cada valor de energia. 
No segundo cálculo o valor da intensidade da transição de $113 \mathrm{keV}$ foi utilizado como referência, em lugar do valor correspondente à transição de $208 \mathrm{keV}$. Uma média entre os valores obtidos no primeiro e no segundo cálculo forneceu o valor final das probabilidades de emissão para as transições de 136 e $249 \mathrm{keV}$.

Uma análise minuciosa dos picos é de extrema importância, uma vez que as áreas destes são muito baixas quando comparadas às dos picos de $208 \mathrm{keV} \mathrm{e}$ $113 \mathrm{keV}$. Alguns destes picos, como é o caso do pico de $71 \mathrm{keV}$ são tão pequenos quanto os picos gerados por outros efeitos que não correspondem a nenhuma transição, como se pode notar na figura (4.1). Os picos de 136 e $249 \mathrm{keV}$ também são muito pequenos quando comparados aos de $208 \mathrm{keV}$, como se nota na figura.

O detalhamento na definição do background (BG) dos picos de 136 e 249 $\mathrm{keV}$ influencia significativamente na área líquida resultante. Uma vez que o pico é muito pequeno, a menor alteração no cálculo do $B G$ afeta consideravelmente o valor da intensidade calculada. Para solucionar este problema com o devido cuidado, foram adotados dois procedimentos: o primeiro foi utilizar uma versão mais sofisticada do ALPINO, o ALPINO4, que faz um ajuste mais preciso na região das bases do pico. Mesmo com este detalhamento o resultado não foi satisfatório, pois analisando-se os mesmos picos pelo programa MAESTRO percebia-se que se misturavam com picos vizinhos. Por este motivo foi adotado outro procedimento, segundo o qual os dois picos seriam analisados visualmente através do programa MAESTRO e os valores definidos para pico e $B G$ seriam digitados como dados de entrada no ALPINO1. Esta medida garantiu que cada pico fosse tratado com o devido cuidado através de uma análise individual. O procedimento foi adotado para cada uma das 7 fontes. 


\section{RESULTADOS}

\subsection{Medidas de Impurezas}

Medidas preliminares no espectrômetro de HPGe, com a solução radioativa proveniente do BIPM, mostraram a presença de uma impureza identificada como sendo de ${ }^{177 \mathrm{~m}} \mathrm{Lu}$ (meia vida de 160,4 (3) dias), correspondendo a 0,030(2)\%, na data de referência. Como as medidas só puderam ser feitas cerca de um mês após a data de referência e a meia vida da impureza é muito maior que a meia vida da fonte, a contribuição da impureza aumentou bastante em relação à fonte, representando uma correção de cerca de $0,5 \%$ no valor da atividade, por ocasião das medidas.

\section{Espectrogama gerado pelo HPGe}

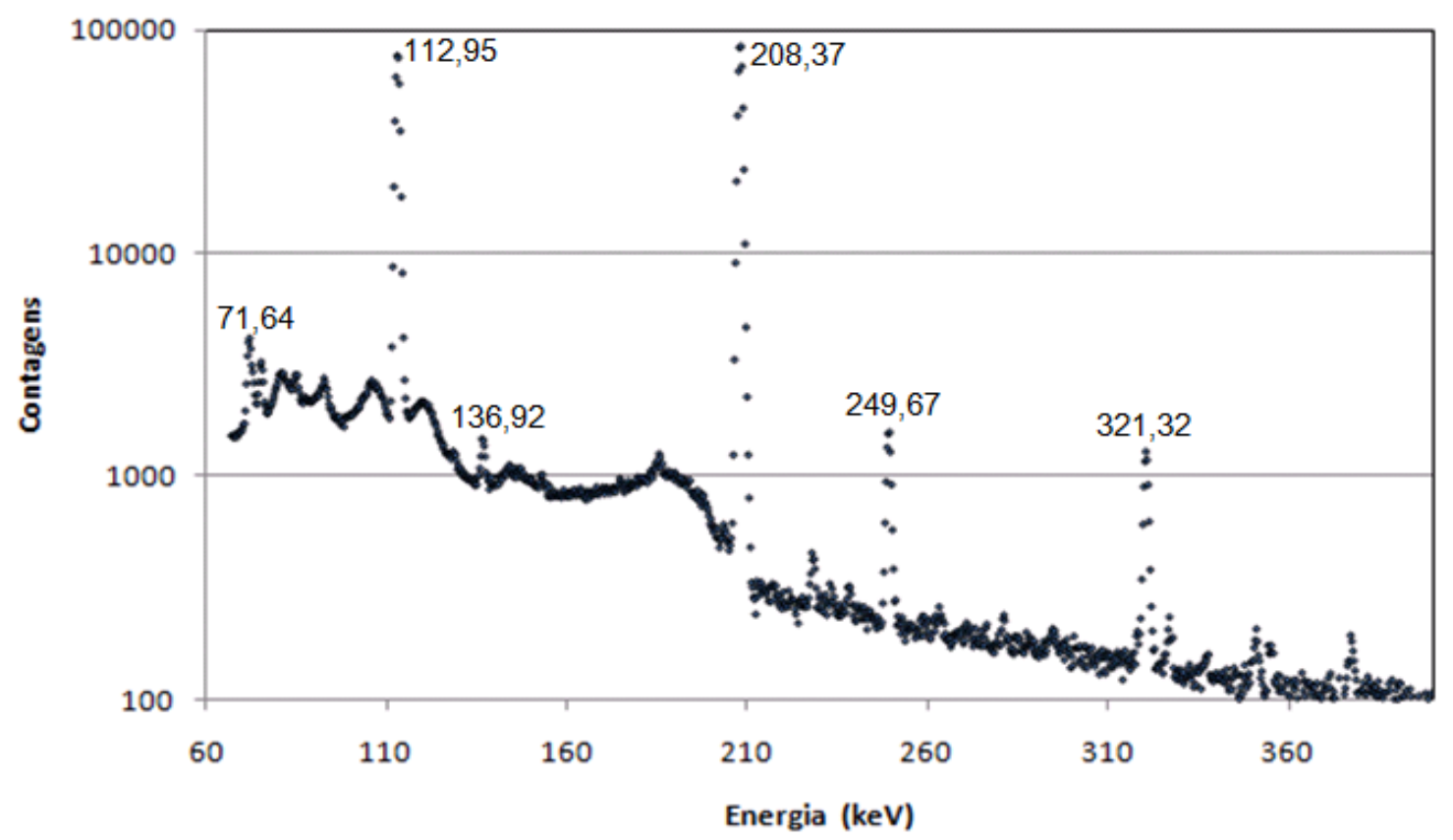

FIGURA 4.1: Espectro gama obtido pelo detector HPGe. Pelo gráfico percebe-se a enorme diferença no número de contagens entre os picos de 112,95 e 208,37 keV e os demais. 
Como se pode observar no espectro gama do detector de HPGe, apresentado na figura (4.1), as transições gama de maior intensidades correspondem às energias de $208 \mathrm{keV}$ e $113 \mathrm{keV}$, com intensidades de 10,38 \% e $6,2 \%$, respectivamente. Por este motivo a "janela" gama para a medida de coincidência $4 \pi \beta-\gamma$ foi escolhida incluindo estes dois picos.

Também aparecem no gráfico da figura (4.1) os picos de 71,64, 136,92, 249,67 e $321,32 \mathrm{keV}$. Todas estas transições tiveram suas intensidades medidas a partir de novas fontes com atividade maior do que as primeiras, uma vez que as intensidades destes picos são muito menores do que as dos picos de $208 \mathrm{keV}$ e 113 $\mathrm{keV}$. No entanto, como os valores de intensidade das transições de 71,64 e 321,32 $\mathrm{keV}$ apresentaram incertezas muito altas os valores de intensidade correspondentes a estas transições não foram incluídos neste trabalho.

\subsection{Comparação dos espectros experimental e teórico do detector de $\mathrm{Nal}$ (TI)}

A figura (4.2) mostra o espectro teórico calculado pelo código ESQUEMA, comparado com o espectro experimental obtido pelo $\mathrm{Nal}(\mathrm{TI})$. Pela figura percebe-se um bom acordo entre o espectro teórico e o experimental. No espectro experimental nota-se um pequeno pico correspondente a $83 \mathrm{keV}$, que não se nota no espectro teórico. Este pico é produzido pelos raios $X$ (gerados pela interação dos fótons de radiação gama com os átomos do detector) que escapam do cintilador $\mathrm{Nal}(\mathrm{Tl})$ e, portanto, não depositam sua energia no detector. A simulação não pôde reproduzir o pico de $83 \mathrm{keV}$ porque para isto seria necessário um tempo de processamento muito maior. Entretanto, como a "janela" adotada experimentalmente inclui o pico de $83 \mathrm{keV}$, conclui-se que a simulação está correta porque a contribuição do raio $\mathrm{X}$ está incluída no pico de 113 keV. 


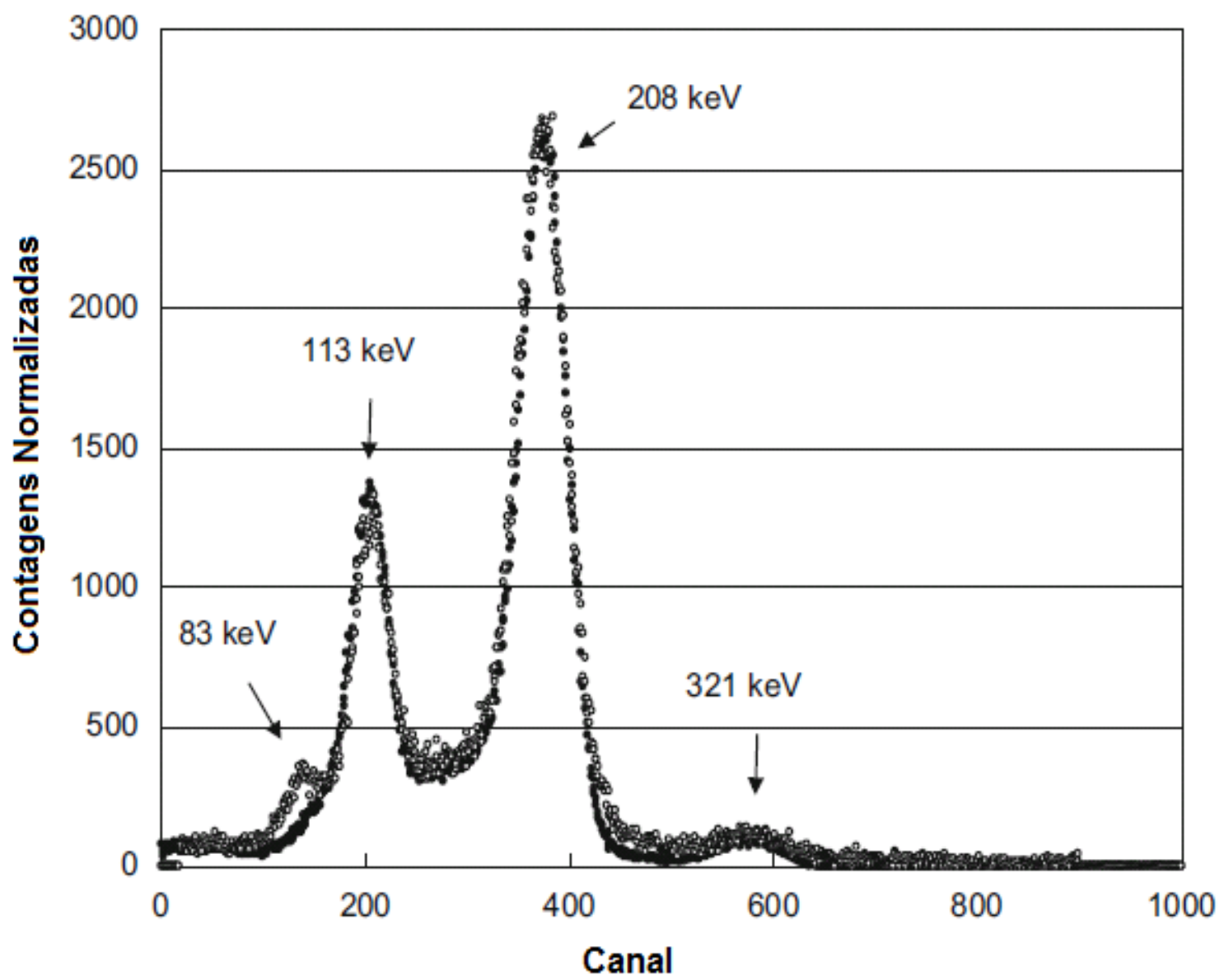

FIGURA 4.2: Espectro gama obtido pelo detector $\mathrm{NaI}(\mathrm{TI})$ do sistema de coincidência. Os pontos brancos representam os dados experimentais e os pontos pretos representam os dados obtidos pela simulação com o Monte Carlo, usando o código ESQUEMA.

\subsection{Curva de extrapolação da eficiência}

Dentre todas as fontes medidas a que apresentou maior valor de eficiência beta foi a fonte 14331. Esta fonte teve sua eficiência alterada por meio da inserção de absorvedores de Collodion. 
TABELA 4.1 : Variação do parâmetro de ineficiência por meio da inserção de absorvedores de Collodion, juntamente com os valores calculados de atividade e a reta ajustada. Os valores de $\boldsymbol{N}_{\boldsymbol{\beta}} \boldsymbol{N}_{\gamma} / \boldsymbol{N}_{\boldsymbol{c}}$ e da reta ajustada estão em MBq.

Janela de $113 \mathrm{keV}$

Janela de $208 \mathrm{keV}$

\begin{tabular}{ccccccc}
$\begin{array}{c}\text { Quant. } \\
\text { Abs. }\end{array}$ & $\boldsymbol{N}_{\boldsymbol{\beta}} \boldsymbol{N}_{\gamma} / \boldsymbol{N}_{\boldsymbol{c}}$ & $\frac{\left(\mathbf{1}-\mathbf{N}_{\boldsymbol{\beta}} / \mathbf{N}_{\gamma}\right)}{\left(\mathbf{N}_{\boldsymbol{\beta}} / \mathbf{N}_{\gamma}\right)}$ & $\begin{array}{c}\text { Reta } \\
\text { ajustada }\end{array}$ & $\boldsymbol{N}_{\boldsymbol{\beta}} \boldsymbol{N}_{\gamma} / \boldsymbol{N}_{\boldsymbol{c}}$ & $\frac{\left(\mathbf{1}-\mathbf{N}_{\boldsymbol{\beta}} / \mathbf{N}_{\boldsymbol{\gamma}} \text {. }\right.}{\left(\mathbf{N}_{\boldsymbol{\beta}} / \mathbf{N}_{\gamma}\right)}$ & $\begin{array}{c}\text { Reta } \\
\text { ajustada }\end{array}$ \\
\hline 1 & 3,490 & 0,1379 & 3,485 & 3,301 & 0,0767 & 3,315 \\
2 & 3,494 & 0,1571 & 3,506 & 3,335 & 0,1051 & 3,321 \\
3 & 3,472 & 0,1563 & 3,505 & 3,323 & 0,1142 & 3,322 \\
4 & 3,538 & 0,1814 & 3,533 & 3,344 & 0,1059 & 3,323 \\
5 & 3,553 & 0,1899 & 3,542 & 3,329 & 0,1161 & 3,324 \\
6 & 3,514 & 0,1781 & 3,529 & 3,348 & 0,1232 & 3,325 \\
8 & 3,579 & 0,2116 & 3,566 & 3,303 & 0,0975 & 3,326 \\
10 & 3,554 & 0,2100 & 3,565 & 3,323 & 0,1259 & 3,331 \\
14 & 3,619 & 0,2483 & 3,607 & 3,324 & 0,1479 & 3,336 \\
18 & 3,666 & 0,2862 & 3,649 & 3,331 & 0,1685 & 3,345 \\
24 & 3,718 & 0,3470 & 3,716 & 3,338 & 0,2092 & 3,352 \\
30 & 3,822 & 0,4182 & 3,795 & 3,383 & 0,2414 & 3,362 \\
36 & 3,795 & 0,4420 & 3,822 & 3,301 & 0,2882 & 3,315 \\
\hline
\end{tabular}

A tabela 4.1 mostra a variação do parâmetro de ineficiência $\frac{\left(1-N_{\beta} / N_{\gamma}\right)}{\left(N_{\beta} / N_{Y}\right)}$, conforme o número de camadas de Collodion aumenta. A tabela também apresenta o valor da atividade calculada por $N_{\beta} N_{\gamma} / N_{c}$, já corrigido para decaimento radioativo e para a impureza, para cada uma das "janelas" gama além dos valores da reta ajustada. 
A tabela 4.2 mostra as incertezas parciais envolvidas na medida da atividade para a janela gama de $113 \mathrm{keV}$.

TABELA 4.2: Incertezas parciais associadas à medida de atividade da fonte 14331 para a janela gama de $113 \mathrm{keV}$ (em percentagem).

\begin{tabular}{ccccccc}
\hline $\begin{array}{c}\text { Quant. } \\
\text { Abs. }\end{array}$ & $\boldsymbol{N}_{\beta}$ & Eficiência & Decaimento & Impureza & Massa & Total \\
\hline & & & & & & \\
1 & 0,03 & 0,15 & 0,24 & 0,10 & 0,10 & 0,32 \\
2 & 0,03 & 0,15 & 0,24 & 0,10 & 0,10 & 0,32 \\
4 & 0,04 & 0,16 & 0,24 & 0,10 & 0,10 & 0,32 \\
3 & 0,03 & 0,16 & 0,24 & 0,10 & 0,10 & 0,32 \\
5 & 0,03 & 0,17 & 0,24 & 0,10 & 0,10 & 0,33 \\
6 & 0,03 & 0,13 & 0,25 & 0,10 & 0,10 & 0,32 \\
10 & 0,04 & 0,19 & 0,25 & 0,10 & 0,10 & 0,35 \\
14 & 0,05 & 0,22 & 0,25 & 0,10 & 0,10 & 0,37 \\
18 & 0,04 & 0,21 & 0,26 & 0,10 & 0,10 & 0,37 \\
24 & 0,04 & 0,23 & 0,26 & 0,10 & 0,10 & 0,38 \\
30 & 0,04 & 0,24 & 0,26 & 0,10 & 0,10 & 0,38 \\
36 & 0,05 & 0,27 & 0,26 & 0,10 & 0,10 & 0,40 \\
\hline
\end{tabular}


TABELA 4.3: Incertezas parciais associadas à medida de atividade da fonte 14331 para a janela gama de $208 \mathrm{keV}$ (em percentagem).

\begin{tabular}{ccccccc}
\hline $\begin{array}{c}\text { Quant. } \\
\text { Abs. }\end{array}$ & $\boldsymbol{N}_{\beta}$ & Eficiência & Decaimento & Impureza & Massa & Total \\
\hline 1 & 0,03 & 0,27 & 0,25 & 0,10 & 0,10 & 0,39 \\
2 & 0,03 & 0,29 & 0,21 & 0,10 & 0,10 & 0,38 \\
3 & 0,04 & 0,29 & 0,25 & 0,10 & 0,10 & 0,41 \\
4 & 0,03 & 0,31 & 0,21 & 0,10 & 0,10 & 0,40 \\
5 & 0,03 & 0,32 & 0,21 & 0,10 & 0,10 & 0,40 \\
6 & 0,05 & 0,24 & 0,25 & 0,10 & 0,10 & 0,37 \\
8 & 0,03 & 0,35 & 0,21 & 0,10 & 0,10 & 0,43 \\
10 & 0,04 & 0,35 & 0,26 & 0,10 & 0,10 & 0,46 \\
14 & 0,02 & 0,42 & 0,21 & 0,10 & 0,10 & 0,49 \\
18 & 0,03 & 0,40 & 0,20 & 0,10 & 0,10 & 0,47 \\
24 & 0,03 & 0,43 & 0,21 & 0,10 & 0,10 & 0,49 \\
30 & 0,04 & 0,45 & 0,26 & 0,10 & 0,10 & 0,54 \\
36 & 0,04 & 0,27 & 0,26 & 0,10 & 0,10 & 0,40 \\
\hline
\end{tabular}

Com base na tabela (4.1) pode-se construir um gráfico com os dados experimentais e a reta ajustada e extrapolada para o valor de ineficiência igual a 0 . A figura (4.3) mostra o gráfico construído com base nos dados obtidos para a janela gama de $113 \mathrm{keV}$. O valor da atividade obtido pela extrapolação da reta é de $3,332(16) \mathrm{MBq}$. O mesmo procedimento foi adotado para os valores obtidos para a janela gama de $208 \mathrm{keV}$ (figura 4.4) obtendo-se a atividade por meio da extrapolação da reta com o valor de 3,298 (18) $\mathrm{MBq}$ 


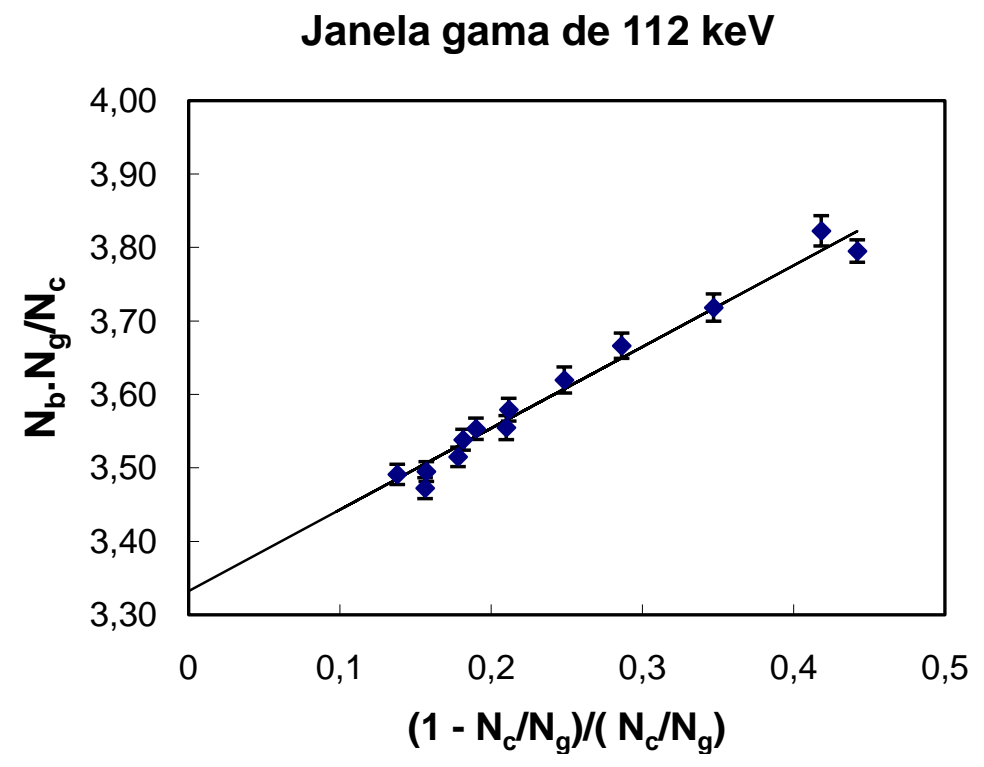

FIGURA 4.3: Ajuste de reta e extrapolação para o valor de ineficiência igual a zero com base nos dados obtidos para a janela gama de $113 \mathrm{keV}$.

Janela gama de $208 \mathrm{keV}$

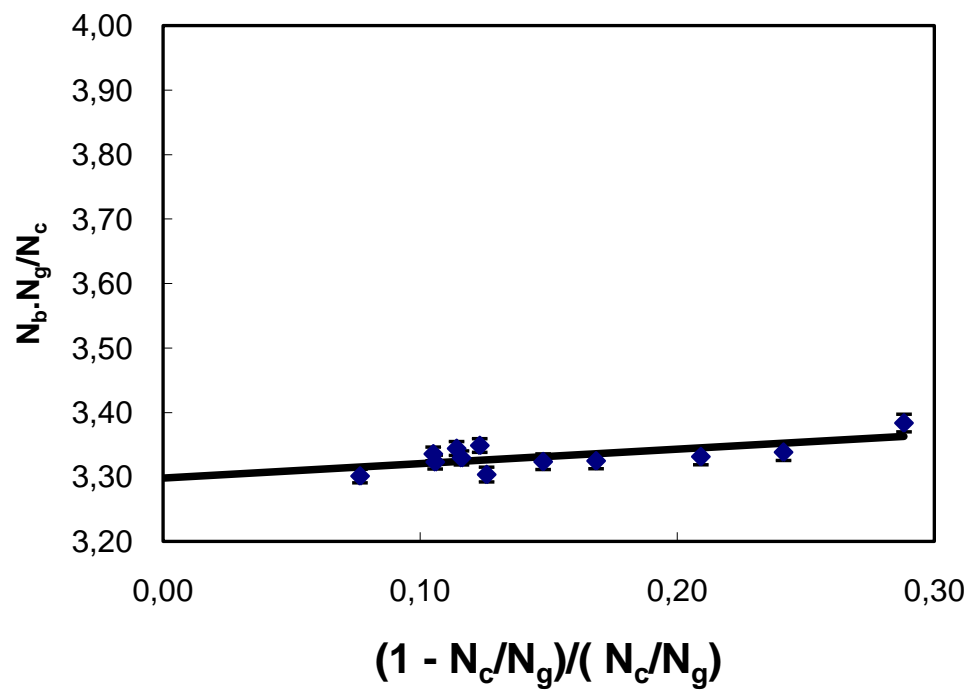

FIGURA 4.4: Ajuste de reta e extrapolação para o valor de ineficiência igual a zero com base nos dados obtidos para a janela gama de $208 \mathrm{keV}$. 
Os dados das demais fontes medidas, obtidos para a janela gama de $113 \mathrm{keV}$ e para a janela de $208 \mathrm{keV}$ encontram-se nas tabelas (4.4) e (4.5), respectivamente.

TABELA 4.4: Dados das demais fontes medidas, para a janela gama de $113 \mathrm{KeV}$.

\begin{tabular}{cccc}
\hline Fonte & $\mathbf{( g )}$ & Ineficiência & $\begin{array}{c}\text { Atividade } \\
(\mathbf{M B q})\end{array}$ \\
\hline 14322 & 0,040708 & 0,29187 & 3,430 \\
14323 & 0,041463 & 0,19395 & 3,395 \\
14324 & 0,052018 & 0,09752 & 3,458 \\
14325 & 0,041084 & 0,14461 & 3,571 \\
14326 & 0,041322 & 0,11557 & 3,463 \\
14328 & 0,041568 & 0,11242 & 3,471 \\
14329 & 0,038157 & 0,10274 & 3,484 \\
14330 & 0,054517 & 0,35660 & 3,342 \\
14332 & 0,040441 & 0,28297 & 3,062 \\
\hline
\end{tabular}


TABELA 4.5: Dados das demais fontes medidas, para a janela gama de $208 \mathrm{KeV}$.

\begin{tabular}{|c|c|c|c|}
\hline \multicolumn{3}{|c|}{ Massa } & Atividade \\
\hline Fonte & (g) & Ineficiência & (MBq) \\
\hline 14322 & 0,040708 & 0,1929 & 3,165 \\
\hline 14323 & 0,041463 & 0,1298 & 3,211 \\
\hline 14324 & 0,052018 & 0,1888 & 3,186 \\
\hline 14325 & 0,041084 & 0,1440 & 3,194 \\
\hline 14326 & 0,041322 & 0,1569 & 4,887 \\
\hline 14328 & 0,041568 & 0,1242 & 4,690 \\
\hline 14329 & 0,038157 & 0,1095 & 5,043 \\
\hline 14330 & 0,054517 & 0,2584 & 3,099 \\
\hline 14332 & 0,040441 & 0,2013 & 2,865 \\
\hline
\end{tabular}

As incertezas associadas às medidas das demais fontes, para a janela gama de $113 \mathrm{KeV}$ e de $208 \mathrm{keV}$ são apresentadas nas tabelas (4.6) e (4.7), respectivamente. 
TABELA 4.6: Incertezas parciais associadas à medida de atividade das demais fontes, para a janela gama de $113 \mathrm{keV}$ (em percentagem).

\begin{tabular}{ccccccc}
\hline Fonte & $\boldsymbol{N}_{\beta}$ & Eficiência & Decaimento & Impureza & Massa & Total \\
\hline 14322 & 0,03 & 0,24 & 0,10 & 0,24 & 0,10 & 0,36 \\
14323 & 0,03 & 0,23 & 0,10 & 0,30 & 0,10 & 0,40 \\
14324 & 0,04 & 0,20 & 0,10 & 0,29 & 0,10 & 0,38 \\
14325 & 0,03 & 0,24 & 0,10 & 0,21 & 0,10 & 0,35 \\
14326 & 0,04 & 0,26 & 0,10 & 0,25 & 0,10 & 0,38 \\
14328 & 0,03 & 0,23 & 0,10 & 0,24 & 0,10 & 0,36 \\
14329 & 0,04 & 0,24 & 0,10 & 0,24 & 0,10 & 0,36 \\
14330 & 0,02 & 0,27 & 0,10 & 0,21 & 0,10 & 0,37 \\
14332 & 0,03 & 0,30 & 0,10 & 0,24 & 0,10 & 0,41
\end{tabular}

TABELA 4.7: Incertezas parciais associadas à medida de atividade das demais fontes, para a janela gama de $208 \mathrm{keV}$ (em percentagem).

\begin{tabular}{clccccc}
\hline Fonte & $\boldsymbol{N}_{\beta}$ & Eficiência & Decaimento & Impureza & Massa & Total \\
\hline 14322 & 0,03 & 0,13 & 0,10 & 0,20 & 0,10 & 0,28 \\
14323 & 0,03 & 0,12 & 0,10 & 0,21 & 0,10 & 0,28 \\
14324 & 0,02 & 0,10 & 0,10 & 0,21 & 0,10 & 0,27 \\
14325 & 0,03 & 0,12 & 0,10 & 0,21 & 0,10 & 0,28 \\
14326 & 0,05 & 0,26 & 0,10 & 0,28 & 0,10 & 0,41 \\
14328 & 0,05 & 0,24 & 0,10 & 0,28 & 0,10 & 0,40 \\
14329 & 0,05 & 0,27 & 0,10 & 0,28 & 0,10 & 0,42 \\
14330 & 0,03 & 0,15 & 0,10 & 0,20 & 0,10 & 0,29 \\
14332 & 0,03 & 0,17 & 0,10 & 0,21 & 0,10 & 0,31 \\
\hline
\end{tabular}




\subsection{Interpolação dos dados experimentais com os valores obtidos pela simulação}

A figura (4.5) mostra a curva de extrapolação experimental normalizada, obtida através da variação da eficiência do detector, aumentando-se a espessura do absorvedor, para uma mesma fonte. A partir desta curva a correção de extrapolação foi obtida para cada uma das outras nove fontes.

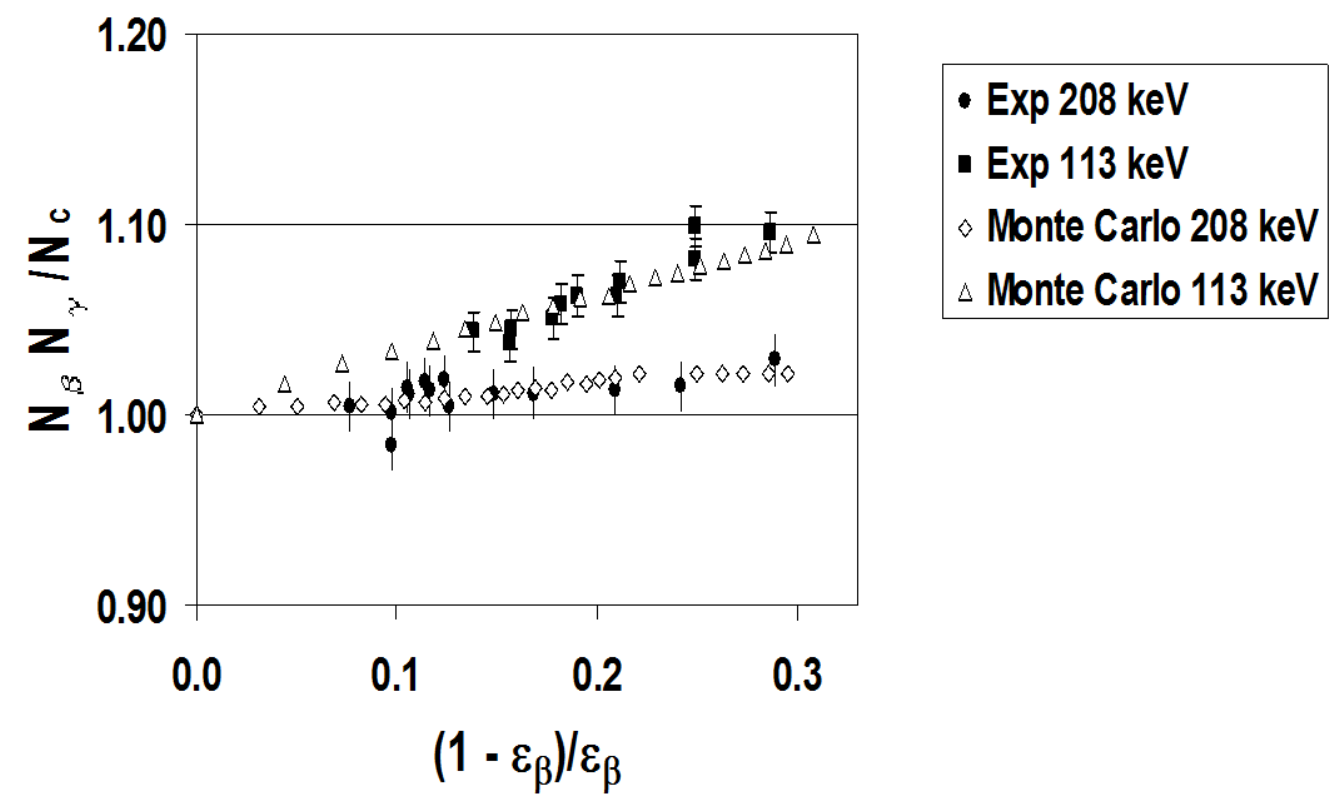

FIGURA 4.5: Curva de extrapolação normalizada para o ${ }^{177} \mathrm{Lu}$. Os pontos experimentais são plotados juntamente com os pontos obtidos pela simulação. $O$ eixo $x$ corresponde à ineficiência relativa $\left(1-\varepsilon_{\beta}\right) / \varepsilon_{\beta}$, que também pode ser obtido por $\frac{\left(1-\mathbf{N}_{\boldsymbol{\beta}} / \mathbf{N}_{\boldsymbol{\gamma}}\right)}{\left(\mathbf{N}_{\boldsymbol{\beta}} / \mathbf{N}_{\boldsymbol{\gamma}}\right)}$.

Nota-se na figura um bom acordo entre os valores experimentais obtidos para a fonte 14331 e os valores obtidos pela simulação por Monte Carlo. A extrapolação utilizando os valores obtidos pela simulação é melhor do que a 
extrapolação utilizando um ajuste de reta. Isto por que a simulação apresenta um comportamento que corresponde mais fielmente ao comportamento dos dados obtidos experimentalmente.

$\mathrm{Na}$ figura (4.5) os valores experimentais são apresentados normalizados pela média da razão $\left(N_{\beta} N_{\gamma} / N_{c}\right)_{\exp } /\left(N_{\beta} N_{\gamma} / N_{c}\right)_{M C}$ que é o valor da atividade da fonte, prevista pelo cálculo de Monte Carlo.

Percebe-se na figura (4.5) que a inclinação da curva formada pelos pontos correspondentes à "janela" gama de $113 \mathrm{keV}$ é maior do que a da curva correspondente à "janela" gama de $208 \mathrm{keV}$. Isto se deve ao valor alto do coeficiente de conversão interna associado à transição de $113 \mathrm{keV}$. O valor final obtido para atividade, na data de referência (01/05/09), foi de 3,277(29) MBq g ${ }^{-1}$.

O gráfico da figura (4.6) apresenta a atividade específica em $\mathrm{MBq} \cdot \mathrm{g}^{-1}$ obtida por cada laboratório participante da comparação internacional patrocinada pelo BIPM.

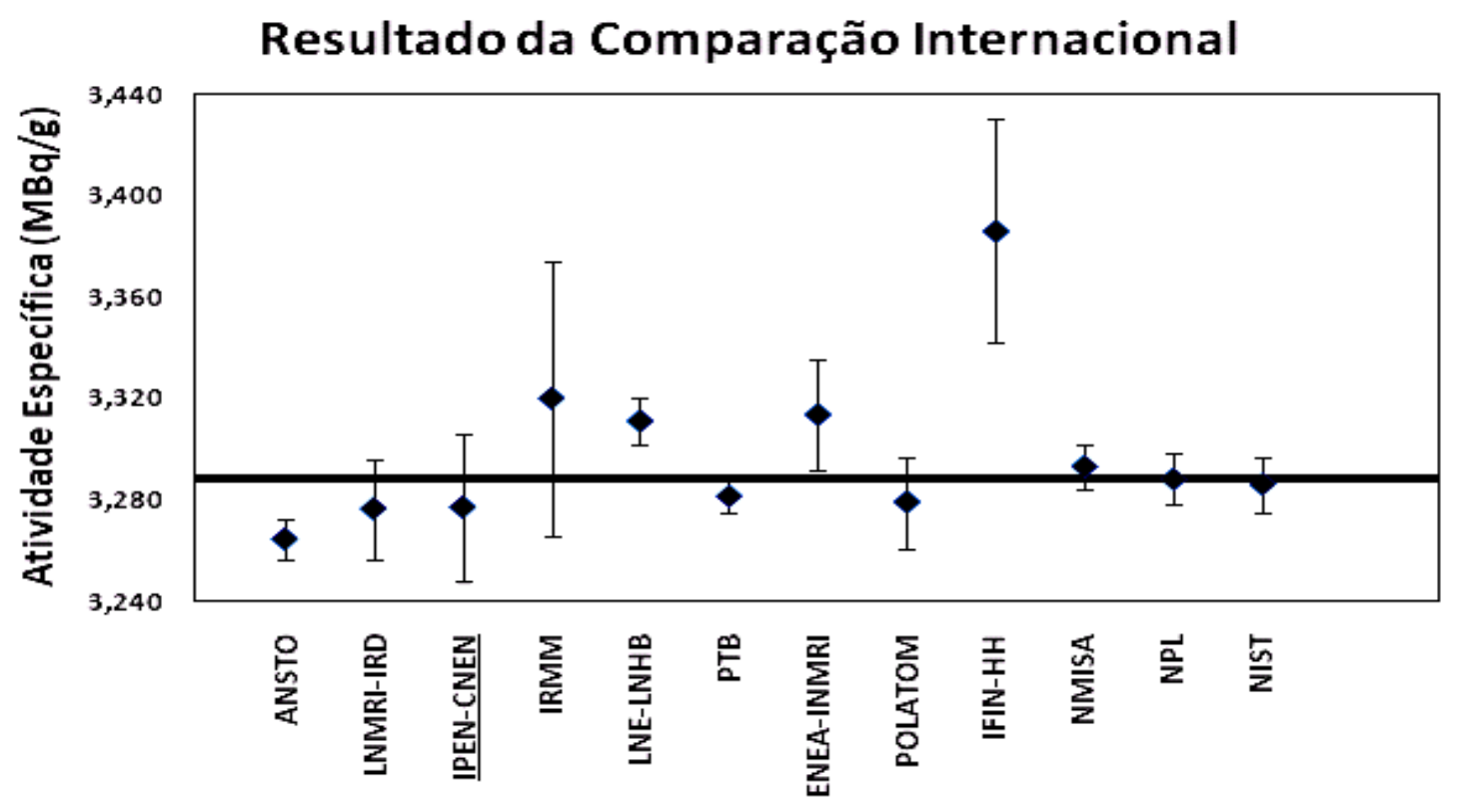

FIGURA 4.6: A linha horizontal representa a média dos valores obtidos na comparação internacional. O ponto correspondente ao laboratório IPEN-CNEN representa o valor obtido neste trabalho. 
O valor obtido neste trabalho está muito próximo da média, que é de $3,288(5) \mathrm{MBq} \cdot \mathrm{g}^{-1}$, o que significa que a metodologia empregada pode ser considerada satisfatória.

\subsection{Obtenção da Curva de Eficiência em Função da Energia Gama}

A curva de eficiência em função da energia gama, obtida utilizando-se os dados das fontes-padrão, é mostrada na figura (4.7).

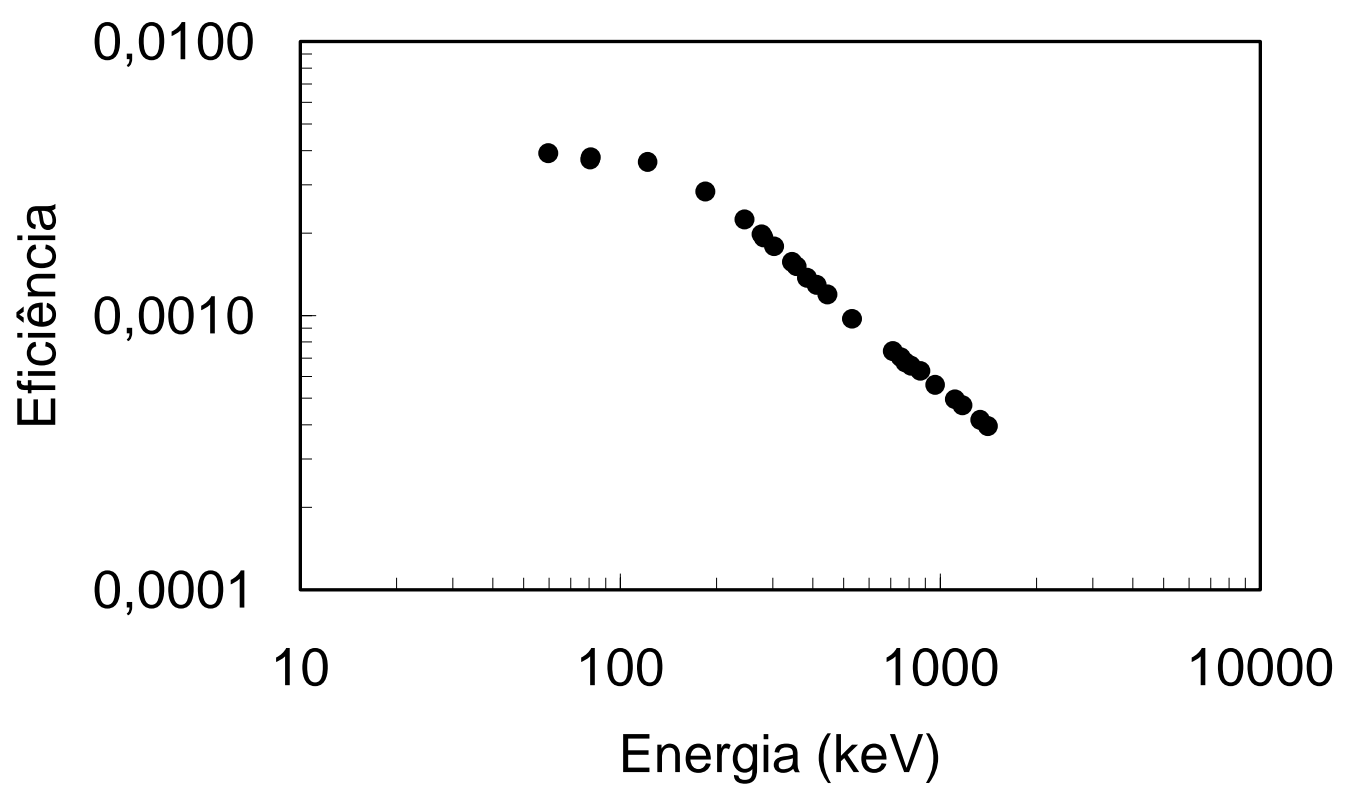

FIGURA 4.7 : Curva de eficiência de pico em função da energia gama, para o espectrômetro de HPGe.

A estes pontos experimentais, foi ajustado um polinômio de grau 5 em escala log-log. Os parâmetros e a matriz de covariância correspondentes para a 
curva de eficiência são apresentados na tabela (4.8). O valor de Qui-Quadrado reduzido resultou 0,96 indicando um ajuste satisfatório.

TABELA 4.8: Parâmetros e matriz de covariância obtidos pelo ajuste da curva de eficiência do HPGe. A função é um polinômio de grau 5, ajustado em uma escala log-log, entre energia e eficiência dos raios gama.

\begin{tabular}{|c|c|c|c|c|c|c|c|c|}
\hline Parâmetro & Valor & Incerteza & $\begin{array}{l}\text { Matr } \\
\text { covar }\end{array}$ & $\begin{array}{l}\text { iz de } \\
\text { iância }\end{array}$ & & & & \\
\hline $\mathrm{a} 0$ & $2044 \mathrm{E}+02$ & $20,50 \mathrm{E}+01$ & $60,39 E+02$ & & & & & \\
\hline a1 & $-2,34 \mathrm{E}+02$ & $20,30 \mathrm{E}+01$ & $-5,85 E+02$ & $0,37 \mathrm{E}+02$ & & & & \\
\hline a2 & $80,66 \mathrm{E}+01$ & $80,40 \mathrm{E}+00$ & $20,12 \mathrm{E}+02$ & $1,95 \mathrm{E}+02$ & $70,06 \mathrm{E}+01$ & & & \\
\hline a3 & $-1,57 \mathrm{E}+01$ & $10,50 \mathrm{E}+00$ & $-3,80 \mathrm{E}+01$ & $30,49 \mathrm{E}+01$ & $-1,27 \mathrm{E}+01$ & $0,28 \mathrm{E}+00$ & & \\
\hline a4 & $10,40 \mathrm{E}+00$ & 10,30E-01 & $30,37 \mathrm{E}+00$ & $-3,10 \mathrm{E}+00$ & $0,12 \mathrm{E}+00$ & $2,02 \mathrm{E}-01$ & 0,80E-02 & \\
\hline a5 & $-4,91 \mathrm{E}-02$ & $40,70 \mathrm{E}-03$ & $-1,18 \mathrm{E}-01$ & 1,09E-01 & $-3,95 \mathrm{E}-02$ & $0,11 \mathrm{E}-03$ & 6,33E-04 & 0,23E-05 \\
\hline$\chi^{2}$ & 0,96 & & & & & & & \\
\hline
\end{tabular}

A figura (4.8) mostra os resíduos obtidos comparando-se os valores de eficiência ajustados com os valores experimentais. De modo geral, observa-se um bom acordo com os valores ajustados. 


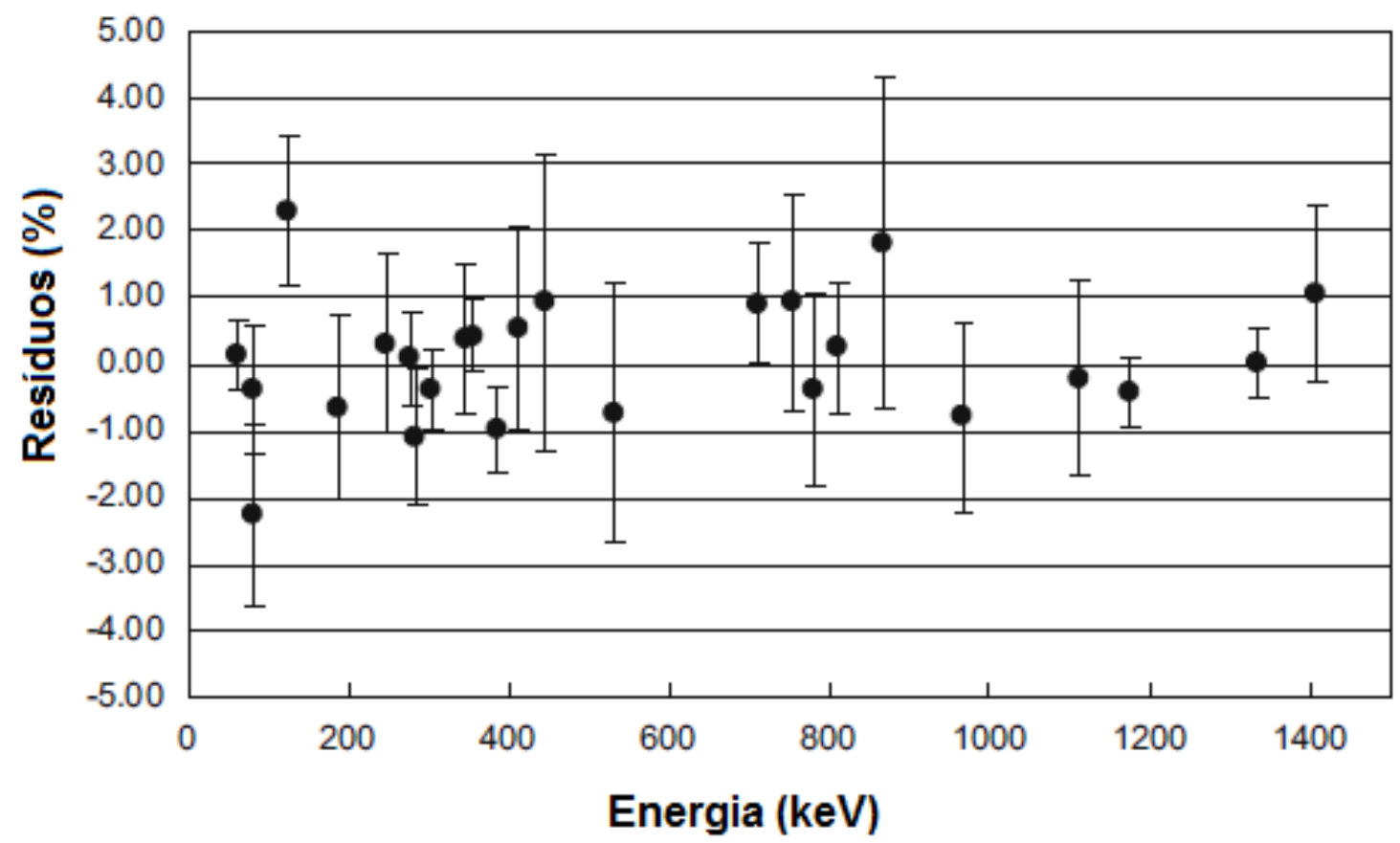

FIGURA 4.8: Resíduos percentuais entre os valores de eficiência ajustados e experimentais em função da energia gama, para o detector de HPGe.

\subsection{Medida da probabilidade de emissão gama das transições gama (113 e $208 \mathrm{keV})$}

Os valores obtidos para as probabilidades de emissão gama por decaimento do ${ }^{177}$ Lu são apresentados na tabela (4.9). Observa-se um bom acordo entre os valores obtidos no presente trabalho e os valores apresentados na literatura. A incerteza obtida no presente trabalho é compatível com os valores da literatura de maior exatidão. 
TABELA 4.9: Probabilidade de emissão gama por decaimento do ${ }^{177} \mathrm{Lu}$, juntamente com a matriz de correlação correspondente. Os valores aparecem em porcentagem.

\begin{tabular}{cccccccc}
\hline $\begin{array}{c}\text { Energia } \\
(\mathbf{k e V})\end{array}$ & $\begin{array}{c}\mathbf{I}_{\gamma} \\
\text { (Presente } \\
\text { trabalho) }\end{array}$ & $\begin{array}{c}\text { Incerteza } \\
\text { total (\%) }\end{array}$ & $\begin{array}{c}\text { Matriz de } \\
\text { correlação }\end{array}$ & $\begin{array}{c}\mathbf{I} \gamma \\
\text { Ref. [30] }\end{array}$ & $\begin{array}{c}\mathbf{I} \gamma \\
\text { Ref. [31] }\end{array}$ & $\begin{array}{c}\mathbf{I} \gamma \\
\text { Ref. [4] }\end{array}$ \\
\hline 112,95 & $6,22(5)$ & 0,82 & 1 & & $6,17(4)$ & $6,4(3)$ & $6,20(7)$ \\
208,37 & $10,35(8)$ & 0,77 & 0,83 & 1 & $10,36(7)$ & $11,0(6)$ & $10,38(7)$ \\
\hline
\end{tabular}

Ref. [30] - Firestone et al., 1996;

Ref. [31] - Schötzig et al., 2001;

Ref. [4] - Bé et al., 2004.

A tabela 4.10 apresenta as incertezas parciais envolvidas na determinação das probabilidades de emissão gama por decaimento, juntamente com o fator de correlação entre os valores correspondentes às energias de $113 \mathrm{keV}$ e $208 \mathrm{keV}$. O fator de correlação entre as intensidades destas duas transições é alto $(0,83)$. Isto pode ser explicado, considerando que as incertezas na atividade, e nas correções para decaimento e impureza são totalmente correlacionadas. 
TABELA 4.10: Quadro de incertezas. A última coluna representa o fator de correlação entre os erros parciais das probabilidades de emissão gama, correspondentes a $113 \mathrm{keV}$ e $208 \mathrm{keV}$, respectivamente.

\begin{tabular}{lccc}
\hline \multicolumn{1}{c}{ Fonte de erros } & \multicolumn{2}{c}{ Erros (\%) } & $\begin{array}{c}\text { Fator de } \\
\text { correlação }\end{array}$ \\
& $\mathbf{1 1 3} \mathbf{~ k e V}$ & $\mathbf{2 0 8} \mathbf{~ k e V}$ & \\
\hline & & & \\
Eficiência do HPGe & 0,67 & 0,55 & 0,6 \\
Atividade & 0,58 & 0,58 & 1 \\
Soma em cascata & 0,04 & 0,04 & 0 \\
Decaimento & 0,15 & 0,15 & 1 \\
Impureza & 0,11 & 0,18 & 1 \\
Estatística & 0,16 & 0,14 & 0 \\
Total correlacionado & 0,80 & 0,75 & \\
Total não & 0,16 & 0,15 & \\
correlacionado & & & 0,83 \\
Total & 0,82 & 0,77 & \\
\hline
\end{tabular}




\subsection{Medida da probabilidade de emissão gama das transições gama (136 e 249 keV)}

Os cálculos das probabilidades de emissão para as transições de $136 \mathrm{e}$ $249 \mathrm{keV}$ foram efetuados conforme o procedimento descrito no item 3.2.2. Para cada uma das sete fontes medidas foi obtido um valor e a média dos valores tendo a transição de $208 \mathrm{keV}$ como referência encontra-se na tabela (4.11). Na tabela (4.12) encontra-se a média dos valores obtidos utilizando-se a transição de $113 \mathrm{keV}$ como referência.

TABELA 4.11: Média dos valores de probabilidades de emissão obtidos para cada uma das 7 fontes de ${ }^{177} \mathrm{Lu}$, tomando como referência a intensidade da transição de $208 \mathrm{keV}$. Os valores de intensidade estão em porcentagem.

\begin{tabular}{ccccc}
$\begin{array}{c}\text { Energia } \\
(\text { keV) }\end{array}$ & $\begin{array}{c}\mathrm{I}_{\gamma} \\
\text { (Média) }\end{array}$ & $\begin{array}{c}\text { Desvio } \\
\text { Padrão da } \\
\text { Média } \\
(\%)\end{array}$ & $\begin{array}{c}\text { Correção } \\
\text { Efeito } \\
\text { Soma }\end{array}$ & Valor Final \\
\hline & & & & \\
136,72 & 0,0457 & 2,0 & 0,99357 & $0,0460(9)$ \\
249,67 & 0,2038 & 1,0 & 0,99618 & $0,2046(21)$
\end{tabular}


TABELA 4.12: Média dos valores obtidos para cada uma das 7 fontes, tomando como referência a intensidade da transição de $113 \mathrm{keV}$. Os valores de intensidade estão em porcentagem.

\begin{tabular}{ccccc}
\hline $\begin{array}{c}\text { Energia } \\
(k e V)\end{array}$ & $\begin{array}{c}\mathrm{I}_{\gamma} \\
\text { (Média) }\end{array}$ & $\begin{array}{c}\text { Desvio } \\
\text { Padrão da } \\
\text { Média } \\
(\%)\end{array}$ & $\begin{array}{c}\text { Correção } \\
\text { Efeito }\end{array}$ & $\begin{array}{c}\text { Valor } \\
\text { Soma }\end{array}$ \\
\hline & \multicolumn{5}{c}{ Final } \\
136,72 & 0,0453 & 2,1 & 0,99357 & $0,0454(10)$ \\
249,67 & 0,2020 & 0,8 & 0,99618 & $0,2020(16)$ \\
\hline
\end{tabular}

A média dos valores finais para as transições de $136,72 \mathrm{keV}$ e de 249,67 keV encontram-se na tabela (4.13) com suas respectivas incertezas.

TABELA 4.13 Probabilidades de emissão gama por decaimento finais para $0^{177} \mathrm{Lu}$ para as transições menos intensas. Os valores aparecem em porcentagem.

\begin{tabular}{|c|c|c|c|c|}
\hline $\begin{array}{l}\text { Energia gama } \\
\qquad(\mathrm{keV})\end{array}$ & $\begin{array}{c}\mathrm{I} \gamma \\
\text { (Presente } \\
\text { trabalho) }\end{array}$ & $\begin{array}{c}\text { I } \gamma \\
\text { Ref. [30] }\end{array}$ & $\begin{array}{c}\text { I } \gamma \\
\text { Ref.[31] }\end{array}$ & $\begin{array}{c}\text { I } \gamma \\
\text { Ref. [4] }\end{array}$ \\
\hline 136,72 & $0,0457(7)$ & $0,048(2)$ & $0,0464(8)$ & $0,0470(7)$ \\
\hline 249,67 & $0,2033(13)$ & $0,212(11)$ & $0,1987(12)$ & $0,2012(21)$ \\
\hline
\end{tabular}


Percebe-se que o valor de intensidade obtido neste trabalho para a transição de 136,72 keV está de acordo, dentro da incerteza, com os valores das três referências. Já o valor obtido para a transição de 249,67 keV está em acordo com a referência [30] e com a referência [4], mas não com a referência [31], que mesmo dentro da incerteza, apresenta um valor menor do que o obtido para este trabalho. No entanto, o valor do presente trabalho é muito próximo da média dos valores encontrados nas três referências, que é de 0,2040(70).

O valor da incerteza não pôde ser menor devido à flutuação dos valores de área dos picos. A estatística poderá ser melhorada medindo-se fontes com atividades maiores do que as que foram utilizadas no presente trabalho. Os resultados para as demais transições de baixa probabilidade de emissão não foram incluídas no presente trabalho porque as incertezas envolvidas seriam ainda maiores e teria pouco impacto para serem apresentadas à comunidade científica interessada neste tipo de dado nuclear. 


\section{CONCLUSÕES}

A atividade específica do ${ }^{177}$ Lu foi obtida com grande exatidão (incerteza de $0,8 \%$ ), indicando que a metodologia empregada no sistema de coincidências $4 \pi \beta-\gamma$ pode ser considerada satisfatória. Pelas figuras (4.1) e (4.4) é possível notar um bom acordo entre os dados experimentais e a simulação por Monte Carlo, mostrando que o modelo teórico é confiável. A tabela (4.9) mostra um bom acordo entre os valores obtidos no presente trabalho e os valores encontrados na literatura, para as probabilidades de emissão gama por decaimento das duas transições mais intensas que foram analisadas. As incertezas para estes valores também são comparáveis com os apresentados na literatura.

O valor das intensidades das transições de 136 e $249 \mathrm{keV}$ do ${ }^{177} \mathrm{Lu}$, obtidos a partir da medida de novas fontes no espectrômetro de HPGe, também mostraram-se compatíveis com os valores encontrados na literatura, dentro da incerteza experimental.

O mesmo procedimento adotado para as linhas de 136 e $249 \mathrm{keV}$ foi seguido também para as linhas de 71 e $321 \mathrm{keV}$, porém a intensidade destas linhas é ainda menor que as demais, o que resultou em um valor de incerteza muito grande. Para um resultado mais satisfatório seria necessário fazer medidas com uma fonte cujo valor de atividade fosse mais alto, para melhorar a estatística e diminuir o valor da incerteza. Deste modo, é sugerido para trabalhos futuros que sejam efetuadas medidas das linhas gama de menor intensidade, por meio da utilização de fontes com valor mais alto de atividade e utilizando-se a mesma metodologia empregada para a determinação das intensidades das transições de 136 e $249 \mathrm{keV}$. Isto permitirá a estatística de contagem e a obtenção de incertezas menores, comparáveis às da literatura. 


\section{REFERÊNCIAS BIBLIOGRÁFICAS}

1 SILVA, G. P. da. Estudo da viabilidade de produção do Lutécio-177 no reator nuclear IEA-R1 do IPEN/CNEN-SP. 2008. Dissertação (Mestrado) Universidade de São Paulo, São Paulo.

2 KNOLL, G.F., Radiation detection and measurement. Fourth edition. John Willey \& Sons, Inc., 2010.

3 EISBERG, R., Física quântica: átomos, moléculas, sólidos, núcleos e partículas. Primeira edição. John Willey \& Sons ,Inc., 1979.

4 BÉ , M.-M.,et al. Tables de Radionucléides, Monographie BIPM-5, ISBN92822-2204-7, 2004.

5 CAMPION, P.J. The Standardization of Radioisotopes by the Beta-Gamma Coincidence Method Using High Efficiency Detectors. Int. J. Appl. Radiat. Iso., 4 p:232-248,1957.

6 BAERG, A. P., 1966, Measurement of radioactivity disintegration rate by the coincidence method. Metrologia, $\underline{2}$ (1), p: 23-32.

7 BAERG, A. P., 1967, Absolute measurement of radioactivity. Metrologia, $\underline{3}$ (4), p: 105-108.

8 BAERG, A.P. The efficiency extrapolation method in coincidence counting. Nuclear Instruments and Methods. 112, p: 143-150, 1973. 
9 MOURA, L.P. Método de coincidência generalizado para a medida absoluta da atividade de radionuclídeos - Aplicação na determinação do coeficiente de conversão interna da transição de 279 keV do ${ }^{203} \mathrm{TI} .1969$. Tese (Doutoramento) - Universidade de Campinas, Campinas.

10 KAWADA, Y., 1972, Extended applications and improvement of the $4 \pi \beta-\gamma$ coincidence method in the standardization of radionuclides. Res. of ETL. Japan, ETL-730.

11 ATTIE, M. R. P., KOSKINAS, M. F., DIAS, M. S., FONSECA, K. A., 1998, Absolute Disintegration Rate Measurements of ${ }^{67} \mathrm{Ga}$. Applied Radiation and Isotopes, Elsevier, Vol. 49, № 9-11, p: 1175-1177.

12 BACCARELLI, A. M., DIAS, M. S., KOSKINAS, M. F., BRANCACCIO, F., 2008 , Standardization of ${ }^{18} \mathrm{~F}$ by Means of $4 \pi(\mathrm{PS}) \beta-\gamma$ Plastic Scintillator Coincidence System. IEEE Transactions on Nuclear Science, Vol. 55, No. 3 , 1767-1773.

13 DIAS, M. S., PIUVEZAM FILHO, H., KOSKINAS, M. F., 2008, Optimization of a coincidence system using plastic scintillators in $\mathbf{4} \pi$ geometry, Applied Radiation and Isotopes, 66, p: 905-908.

14 KOSKINAS, M. F., SILVA, E. A., YAMAZAKI, I. M., DIAS, M. S., 2008, Disintegration rate measurement of ${ }^{182} \mathrm{Ta}$, Applied Radiation and Isotopes, Elsevier, 66, p: 934-936.

15 HILÁRIO, K. A. F. Desenvolvimento de métodos de medida de atividade empregando sistemas de coincidência para radionuclídeos que se desintegram pela dupla emissão $\beta-\beta^{+}$/ captura eletrônica - Aplicação na padronização do ${ }^{192} \mathrm{Ir},{ }^{152} \mathrm{Eu}$ e ${ }^{186} \mathrm{Re} .2002$. Tese (Doutorado) - Universidade de São Paulo, São Paulo. 
16 LAVRAS, W. O. Desenvolvimento de métodos de medida de atividade de radionuclídeos utilizados em medicina nuclear - Aplicação na padronização do ${ }^{51} \mathrm{Cr}$ e ${ }^{153} \mathrm{Sm}$. 2002. Dissertação (Mestrado) - Universidade de São Paulo, São Paulo.

17 MOREIRA, D., S. - Padronização dos radionuclídeos multi-emissores gama ${ }^{166 m} \mathrm{Ho}$ e ${ }^{72} \mathrm{Ga}$ e determinação de suas probabilidades de emissão gama por decaimento. 2005. Tese (Doutorado) - Universidade de São Paulo, São Paulo.

18 SILVA, E.A. da. Determinação da taxa de desintegração e das probabilidades de emissão gama por decaimento do ${ }^{182} \mathrm{Ta} .2008$. Dissertação (Mestrado) - Universidade de São Paulo, Universidade de São Paulo.

19 TOLEDO, F. de. Desenvolvimento de um sistema eletrônico com registro simultâneo de amplitude e instante de ocorrências dos pulsos, aplicado ao método de coincidência $4 \pi \beta-\gamma$. São Paulo: 2009. Dissertação (Mestrado) - Universidade de São Paulo, São Paulo.

20 COX, D.R. and ISHAN,V., A bivariate point process connected with electronic counters. Proceedings of the Royal Society of London, A, 356, p. 149-160, 1977.

21 SMITH, D.L., Improved corrections formulae for coincidence counting. Nuclear Instruments and Methods in Physics Research, v. 152, p. 505519,1978 .

22 DIAS, M. S., 1999. - CONTAC - Código para cálculo da atividade em sistemas de coincidência $4 \pi \beta-\gamma$. Laboratório de Metrologia Nuclear, IPEN, Relatório interno. 
23 Maestro for workgroups - Windows Multi-Channel Analysis, Model A65-B1, version 3.06, EG\&G ORTEC, 1995.

24 DIAS, M. S., 2002 - ALPINO - Código para cálculo da eficiência e atividade de um espectrômetro de raios gama utilizando HPGe. Laboratório de Metrologia Nuclear, IPEN, Relatório interno.

25 DIAS, M. S. , CARDOSO, V. , VANIN, V. R. , KOSKINAS, M. F. 2004, Combination of nonlinear function and mixing method for fitting HPGe efficiency curve in the 59-2754 keV energy range. Applied Radiation and Isotopes, Elsevier, Vol. 60, p: 683-687.

26 TAKEDA, M.N., Determinação da correção para o efeito de soma em cascata para espectrômetros de HPGe pelo método de Monte Carlo. 2001. Dissertação (Mestrado) - Universidade de São Paulo, São Paulo.

27 TAKEDA, M. N. Aplicação do método de Monte Carlo no estudo da padronização de radionuclídeos com esquema de desintegração complexos em sistema de coincidências $4 \pi \beta-\gamma$. 2006. Tese (Doutorado) Universidade de São Paulo, São Paulo.

28 ORNL, 2006. Monte Carlo N-Particle Transport Code System, MCNP5. RSICC Computer Code Collection, Oak Ridge National Laboratory.

29 CAMPION, P.J. Procedures for accurately diluting and dispensing radioactive solutions. Bureau International des Poids et Mesures, Monographie BIPM-1, 1975.

30 FIRESTONE, R.B., et al., Table of Isotopes, eighth edition Wiley, New York., 1996. 
31 SCHÖTZIG, U., SCHRADER, H., SCHÖNFELD, E., GÜNTHER, E., KLEIN, R. Standardisation and decay data of ${ }^{177} \mathrm{Lu}$ and ${ }^{188} \mathrm{Re}$. Appl. Radiat. and Isot. 55, 89. 2001. 